\title{
The Development of Novel Compounds Against Malaria: Quinolines, Triazolpyridines, Pyrazolopyridines and Pyrazolopyrimidines
}

\author{
Luiz C. S. Pinheiro ${ }^{1}\left(\right.$, Lívia M. Feitosa ${ }^{1,2}$, Marilia O. Gandi ${ }^{1,2}$, Flávia F. Silveira ${ }^{1,3}$ and \\ Nubia Boechat $1,2,3, *$ \\ 1 Departamento de Síntese de Fármacos, Instituto de Tecnologia em Fármacos, Farmanguinhos-FIOCRUZ, \\ Fundação Oswaldo Cruz, Rua Sizenando Nabuco 100, Manguinhos, Rio de Janeiro 21041-250, Brazil; \\ luiz.pinheiro@far.fiocruz.br (L.C.S.P.); livia.feitosarj@gmail.com (L.M.F.); \\ mariliaolivagandi@gmail.com (M.O.G.); flaviafernandes_jo23@hotmail.com (F.F.S.) \\ 2 Programa de Pós-Graduação em Farmacologia e Química Medicinal, PPGFQM, Instituto de Ciências \\ Biomédicas, Universidade Federal do Rio de Janeiro, Rio de Janeiro 21041-250, Brazil \\ 3 Programa de Pós-Graduação em Química, PGQu Instituto de Química, Universidade Federal do Rio de \\ Janeiro, Rio de Janeiro 21041-250, Brazil \\ * Correspondence: nubia.boechat@far.fiocruz.br; Tel.: +55-21-3977-2464
}

Academic Editors: Valeria Patricia Sülsen and Albertina Moglioni

Received: 16 October 2019; Accepted: 11 November 2019; Published: 13 November 2019

\begin{abstract}
Based on medicinal chemistry tools, new compounds for malaria treatment were designed. The scaffolds of the drugs used to treat malaria, such as chloroquine, primaquine, amodiaquine, mefloquine and sulfadoxine, were used as inspiration. We demonstrated the importance of quinoline and non-quinoline derivatives in vitro with activity against the W2 chloroquine-resistant (CQR) Plasmodium falciparum clone strain and in vivo against Plasmodium berghei-infected mouse model. Among the quinoline derivatives, new hybrids between chloroquine and sulfadoxine were designed, which gave rise to an important prototype that was more active than both chloroquine and sulfadoxine. Hybrids between chloroquine-atorvastatin and primaquine-atorvastatin were also synthesized and shown to be more potent than the parent drugs alone. Additionally, among the quinoline derivatives, new mefloquine derivatives were synthesized. Among the non-quinoline derivatives, we obtained excellent results with the triazolopyrimidine nucleus, which gave us prototype I that inspired the synthesis of new heterocycles. The pyrazolopyrimidine derivatives stood out as non-quinoline derivatives that are potent inhibitors of the $P$. falciparum dihydroorotate dehydrogenase ( $P f \mathrm{DHODH}$ ) enzyme. We also examined the pyrazolopyridine and pyrazolopyrimidine nuclei.
\end{abstract}

Keywords: malaria; P. falciparum; PfDHODH; quinoline; triazolopyrimidine; pyrazolopyridine; pyrazolopyrimidine; chloroquine; primaquine; mefloquine

\section{Introduction}

Malaria is one of the world's most serious public health problems. According to the latest World Health Organization (WHO) World Malaria Report, no significant gains were achieved in reducing malaria cases in the period from 2015 to 2017. The estimated number of malaria deaths in 2017, at 435,000 , remained broadly unchanged relative to the previous year, which was 445,000 deaths (WHO, 2019) [1].

Due to the high parasitic resistance exhibited by Plasmodium falciparum to most drugs available, monotherapy is no longer used to treat malaria.

To prevent recurrence and delay the development of parasite resistance, the WHO recommends the use of artemisinin-combined therapies (ACTs), which are based on the simultaneous use of drugs with 
different modes of action [2]. Artemisinin derivatives have very short in vivo half-lives, but they are fast acting against the intraerythrocytic asexual blood-stage malaria parasites. Therefore, artemisinin derivatives are coadministered with drugs with longer half-lives [2]. There is an urgent need for novel antimalarials with better safety profiles than current medicines due to the resistance against antimalarial drugs and for the prevention of transmission and relapse of the disease [3-6].

In the recent literature, a number of new antimalarial compounds in different stages of preclinical and clinical development have been described [7-10]. Notably, quinoline derivatives are still the predominant class of antimalarial drugs. [11-13].

The exchange of the quinoline ring with another heterocyclic ring is an important strategy in drug design and the chemical modification of available drugs to develop novel, biologically active compounds. Many heterocyclic compounds have been developed in an attempt to find new drugs to treat malaria [14].

Recent studies by Boechat and coworkers present the design and synthesis of a broad class of quinoline and non-quinoline compounds with anti-P falciparum. These compounds had their structures modified using some medicinal chemistry tools, such as molecular hybridization. The rational sequence of modifications made from the parent drugs and/or prototypes to obtain the novel hybrid compounds is summarized in Figure 1.

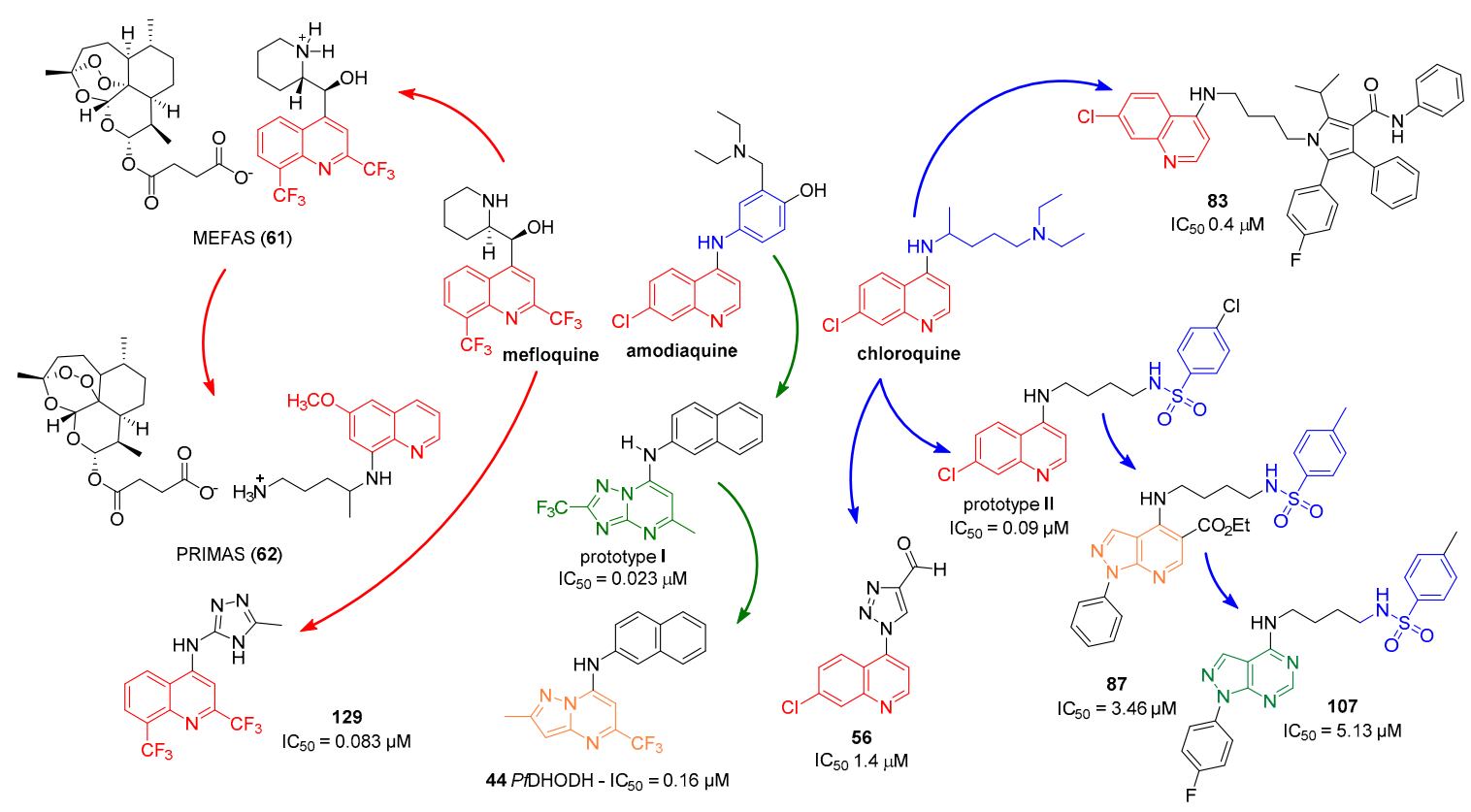

Figure 1. Rational approach to the design quinoline and non-quinoline compounds.

Therefore, twenty-six new derivatives of the $[1,2,4]$ triazolo[1,5-a]pyrimidine system (1-26), with different substituents at the 2, 5 and 7 positions, were designed using standard medicinal chemistry and modeling principles, such as isosteric replacement, based on ring isosterism with the antimalarial drugs mefloquine, chloroquine and amodiaquine (Figure 2) [15]. Additionally, the $\mathrm{CF}_{3}$ group present in mefloquine was added at the 2 position of the triazolopyrimidine ring, and aromatic and aliphatic amine moieties were incorporated at the 7 position, taking into consideration the amodiaquine scaffold. The trifluoromethyl moiety is one of the most widespread fluorine-containing functional groups in bioactive molecules. Due to its highly electronegative feature, it can exert significant electronic influences on neighboring groups. Another advantage is the improvement in lipophilicity, making this moiety useful for targeting molecules to enzymatic active sites [16-18].

The reaction of 3-amino-1,2,4-triazoles $27 \mathbf{a}-\mathbf{c}$ with ethyl acetoacetate or ethyl 4,4,4-trifluoroacetoacetate in toluene under reflux with catalytic $p$-toluenesulfonic acid, for $24 \mathrm{~h}$ produced $[1,2,4]$ triazolo[1,5-a]pyrimidin-7(4H)-ones $\mathbf{2 8 a - \mathbf { d }}$ in $50-90 \%$ yield [19]. Compounds $\mathbf{2 8 a}-\mathbf{d}$ were treated 
with $\mathrm{POCl}_{3}$ under reflux for $6 \mathrm{~h}$ to obtain the respective 7-chloro[1,2,4]triazolo[1,5-a]pyrimidines 29a-d in $58-90 \%$ yield. The nucleophilic aromatic substitution reaction of intermediates $29 a-\mathbf{d}$ with the appropriate amines [20] afforded target compounds [1,2,4]triazolo[1,5-a]pyrimidine derivatives 1-26 in $30-90 \%$ yield (Figure 3 ).

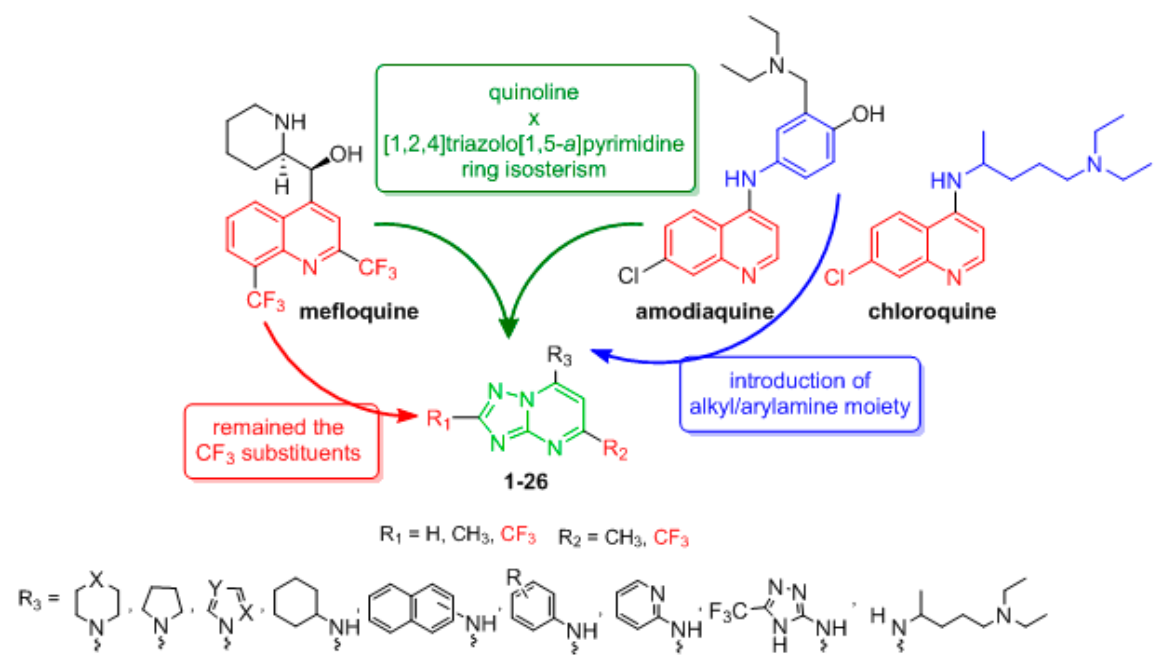

Figure 2. Rational approach to the design of $[1,2,4]$ triazolo[1,5-a]pyrimidine derivatives 1-26.

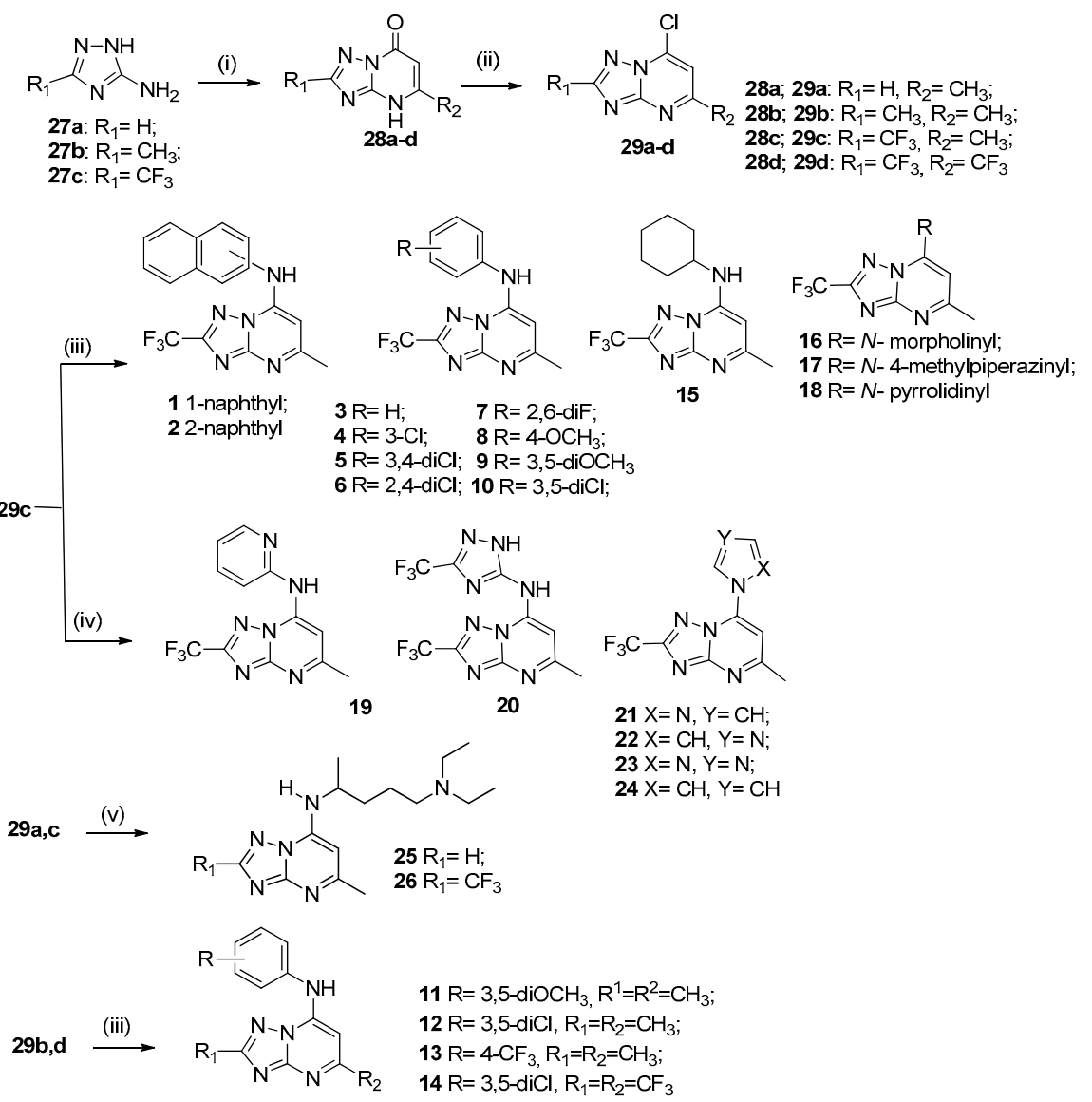

Figure 3. Synthesis of $[1,2,4]$ triazolo[1,5-a]pyrimidines 1-26. Reagents and conditions: (i) ethyl acetoacetate or ethyl 4,4,4-trifluoroacetoacetate, $\mathrm{TsOH}$ (cat.), toluene, reflux, $24 \mathrm{~h}$; (ii) $\mathrm{POCl}_{3}$, reflux, $6 \mathrm{~h}$; (iii) appropriate amine, $\mathrm{EtOH}, 25^{\circ} \mathrm{C}, 16-18 \mathrm{~h}$; (iv) appropriate amine/azol, DMF, $120{ }^{\circ} \mathrm{C}, 12 \mathrm{~h}$; (v) appropriate amine, $\mathrm{EtOH}, 25^{\circ} \mathrm{C}, 43 \mathrm{~h}$. 
Synthesized compounds 1-26 were evaluated in vitro against the W2 chloroquine-resistant (CQR) P. falciparum clone strain, which showed $\mathrm{IC}_{50}$ values in the range of 0.023 to $20 \mu \mathrm{M}$ and did not present toxicity to HepG2 cells. The trifluoromethyl group, as a substituent at the 2 position of the $[1,2,4]$ triazolo[1,5-a]pyrimidine ring, contributed to an increase in anti-P. falciparum activity. Compounds 2 (2-naphthyl; $\left.\mathrm{IC}_{50}=0.023 \mu \mathrm{M}\right), 5\left(3,4-\mathrm{diCl} ; \mathrm{IC}_{50}=0.55 \mu \mathrm{M}\right), 8\left(4-\mathrm{OCH}_{3}\right.$; $\left.\mathrm{IC}_{50}=0.4 \mu \mathrm{M}\right)$, and $13\left(4-\mathrm{CF}_{3} ; \mathrm{IC}_{50}=0.3 \mu \mathrm{M}\right)$ were the most potent of the series. However, the 5-methyl-7- $N^{\prime}$-(N,N-diethylpentane-1,4-diamine)-2-(trifluoromethyl) $[1,2,4]$ triazolo[1,5- $\left.a\right]$ pyrimidine derivative that contained a trifluoromethyl group showed poor antimalarial activity. Derivative 2, which contains a $\beta$-naphthylamine group in its structure at the 7 position, and the trifluoromethyl group at the 2 position, has an important contribution to anti- $P$. falciparum activity when compared with the other derivatives that contain aryl/alkylamine groups at the 7 position. Derivative 2 was therefore used as a prototype compound (prototype I) for future investigations in the search for compounds for the treatment of malaria (Figure 4).

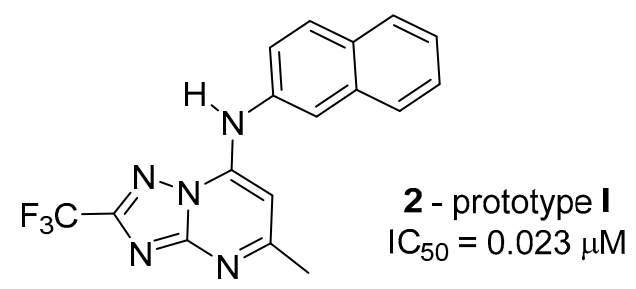

Figure 4. Structure of prototype I.

The inhibition of P. falciparum dihydroorotate dehydrogenase (PfDHODH) has been shown to be an attractive strategy to search for new substances with antiplasmodial activity [21,22]. Synthetic compounds have been identified as inhibitors of class 2 DHODH enzymes. Some $[1,2,4]$ triazolo[1,5-a]pyrimidin-7-amines were discovered by Phillips and coworkers as inhibitors of $P f \mathrm{DHODH}$ [23-26]. Following these good results, new 7-arylaminopyrazolo[1,5- $a$ ]pyrimidines were designed by ring isosterism from prototype I [27]. The [1,2,4]triazolo[1,5- $a$ ]pyrimidine ring was modified to a pyrazolo[1,5- $a$ ]pyrimidine ring and changed by molecular hybridization (Figure 5).

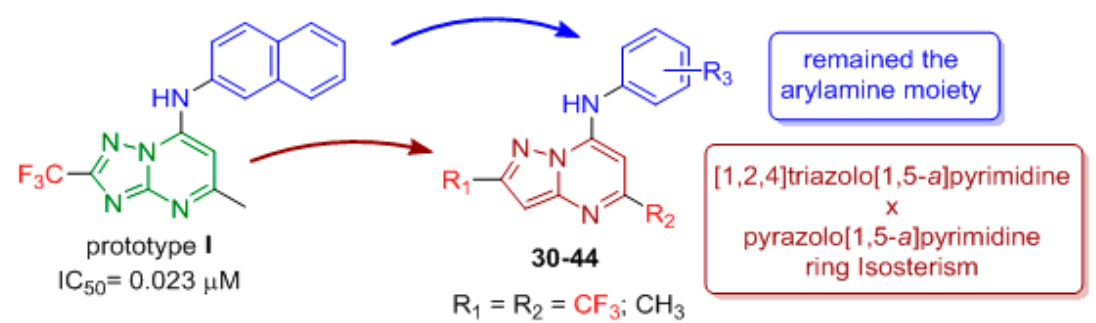

Figure 5. Rational approach to the design of pyrazolo[1,5-a]pyrimidine derivatives $\mathbf{3 0 - 4 4}$.

Different arylamines were incorporated into the structure to investigate the importance of the substituent at the 7 position of the pyrazolopyrimidine nucleus, and the $\beta$-naphthylamine moiety was also incorporated. In a previous work, we observed that a trifluoromethyl group at the 2 position of the triazolopyrimidine ring plays an important role in antiplasmodial activity. This time, $\mathrm{CF}_{3}$ was also added as a substituent in the 2 or 5 position of the pyrazolo[1,5- $a$ ]pyrimidine scaffold to investigate the influence of this group on the anti-P. falciparum activity.

Fifteen compounds, 30-44, were synthesized in $44 \%-92 \%$ yield using the same synthetic methodology described above (Figure 6) [15]. 


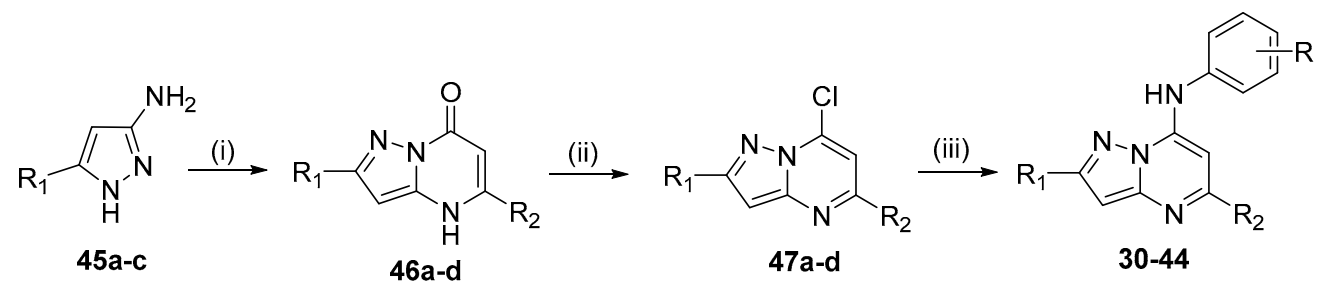

$\mathrm{R}_{1}=\mathrm{R}_{2}=\mathrm{CF}_{3} ; \mathrm{CH}_{3}$

Figure 6. Synthesis of pyrazolo[1,5-a]pyrimidines 30-44. Reagents and conditions: (i) ethyl acetoacetate or ethyl 4,4,4-trifluoroacetoacetate, $\mathrm{TsOH}$ (cat.), toluene, reflux, 20 h; (ii) $\mathrm{POCl}_{3}$, reflux, 4 h; (iii) appropriate amine, $\mathrm{EtOH}, 25^{\circ} \mathrm{C}, 16-18 \mathrm{~h}$.

These compounds were evaluated in vitro against the P. falciparum W2 CQR clone, in vivo against $P$. berghei-infected mouse model, and in vitro as PfDHODH inhibitors. In addition, a molecular docking study was performed to evaluate the possible binding mode of the 7-arylaminopyrazolo[1,5-a]pyrimidine compounds to $P f \mathrm{DHODH}$.

Among the 15 pyrazolopyrimidines synthesized, 13 exhibited anti-P. falciparum activity, with $\mathrm{IC}_{50}$ values ranging from 1.2 to $92.4 \mu \mathrm{M}$. Compounds $33\left(\mathrm{R}_{1}=\mathrm{CF}_{3}, \mathrm{R}_{2}=\mathrm{CH}_{3}\right), 38\left(\mathrm{R}_{1}=\mathrm{CH}_{3}, \mathrm{R}_{2}=\mathrm{CH}_{3}\right)$ and $44\left(\mathrm{R}_{1}=\mathrm{CH}_{3}, \mathrm{R}_{2}=\mathrm{CF}_{3}\right)$ with $\beta$-naphthylamine at the 7 position were the most active. Compounds 33 and 38 exhibited low toxicity and low $\mathrm{IC}_{50}$ values of 1.2 and $5.1 \mu \mathrm{M}$, respectively, and consequently, the highest SI (selectivity index) values of 467.8 and 79.6, respectively. Therefore, compounds 33 and 38 were selected for in vivo in $P$. berghei-infected mouse model. On day 5 upon treatment at $5 \mathrm{mg} / \mathrm{kg}$, administered orally, both compounds reduced parasitemia by $50 \%$. Compound 44 showed the best inhibition of the PfDHODH enzyme with an $\mathrm{IC}_{50}=0.16 \mu \mathrm{M}$, which was more potent than prototype I $\left(\mathrm{IC}_{50}=0.70 \mu \mathrm{M}\right)$, whereas 33 and 38 had $\mathrm{IC}_{50}$ values of 6.0 and $4.0 \mu \mathrm{M}$, respectively.

Compounds that had better activity against $P$. falciparum were also the most active against the PfDHODH enzyme (Figure 7), which indicated that inhibition of this enzyme was one of the potential mechanisms of action of the 7-arylaminepyrazolo[1,5-a]pyrimidines.

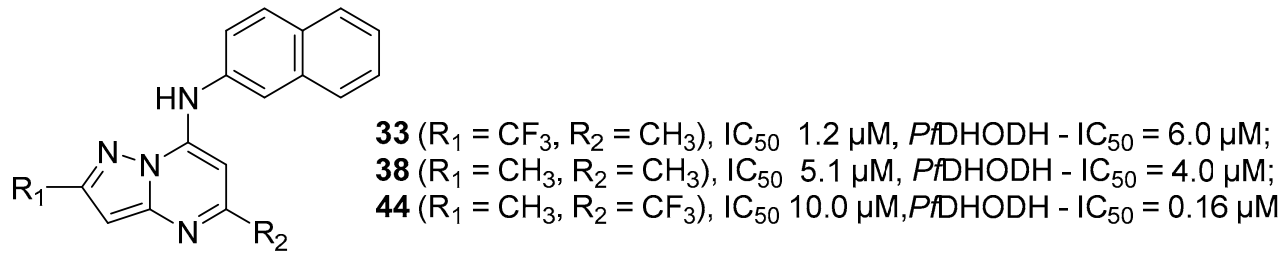

Figure 7. Structure of pyrazolo[1,5-a]pyrimidines 30-44.

The proposed bioisosteric replacement of the $[1,2,4]$ triazolo[1,5-a]pyrimidine ring on prototype $\mathbf{I}$ by the pyrazolo[1,5-a]pyrimidine ring was shown to be a positive proposition according to the molecular docking study. These results demonstrated the potential of 7-arylpyrazolo[1,5- $a$ ]pyrimidine derivatives as inhibitors of $P f \mathrm{DHODH}$ and may represent new leads for developing drugs against malaria.

Although quinoline derivatives continue to dominate the antimalarial drug, new synthetic hybrid compounds have been described in recent literature [28-34]; however, due to resistance to this class of drugs, searching for other analogous compounds is extremely important [35].

In an effort to obtain novel quinoline derivatives for the treatment of malaria, new quinolinyl-1H-1,2,3-triazoles (48-58) were designed to find new compounds with anti-P. falciparum activity [36].

The literature describes several compounds containing a $1 H-1,2,3$-triazole ring with $P$. falciparum activity [37]. Previous works described by our group demonstrated that 1,2,3-triazoles are active against Mycobacterium tuberculosis [38] and Leishmania amazonensis [39]. Therefore, it was planned to connect this ring to the 7-chloroquinoline moiety present in CQ and amodiaquine and incorporate a variety of substituents at the 4 position (Figure 8 ). 


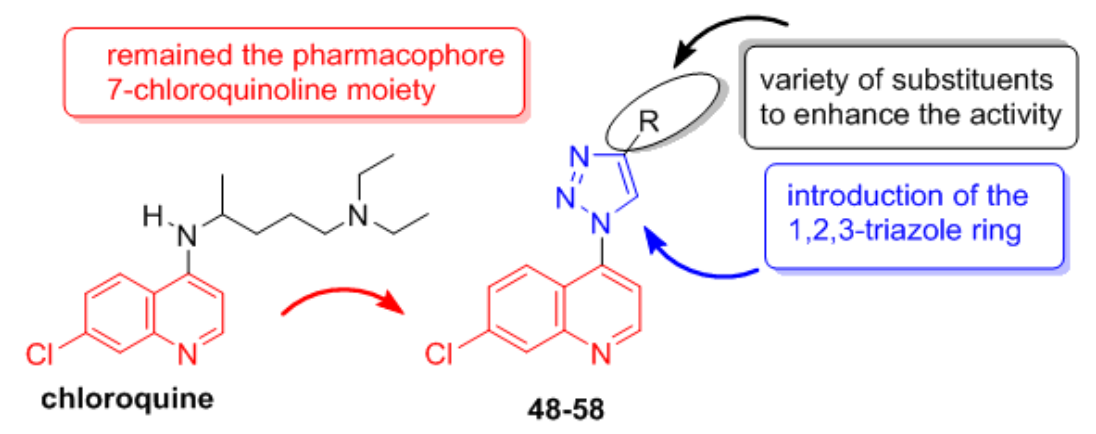

Figure 8. Rational approach to the design of quinoline derivatives 48-58.

The synthetic route that was used to prepare the 7-chloro-4-(1H-1,2,3-triazol-1-yl)quinolines 48-58 is shown in Figure 9.<smiles>[R]c1cn(-c2ccnc3cc(Cl)ccc23)nn1</smiles>

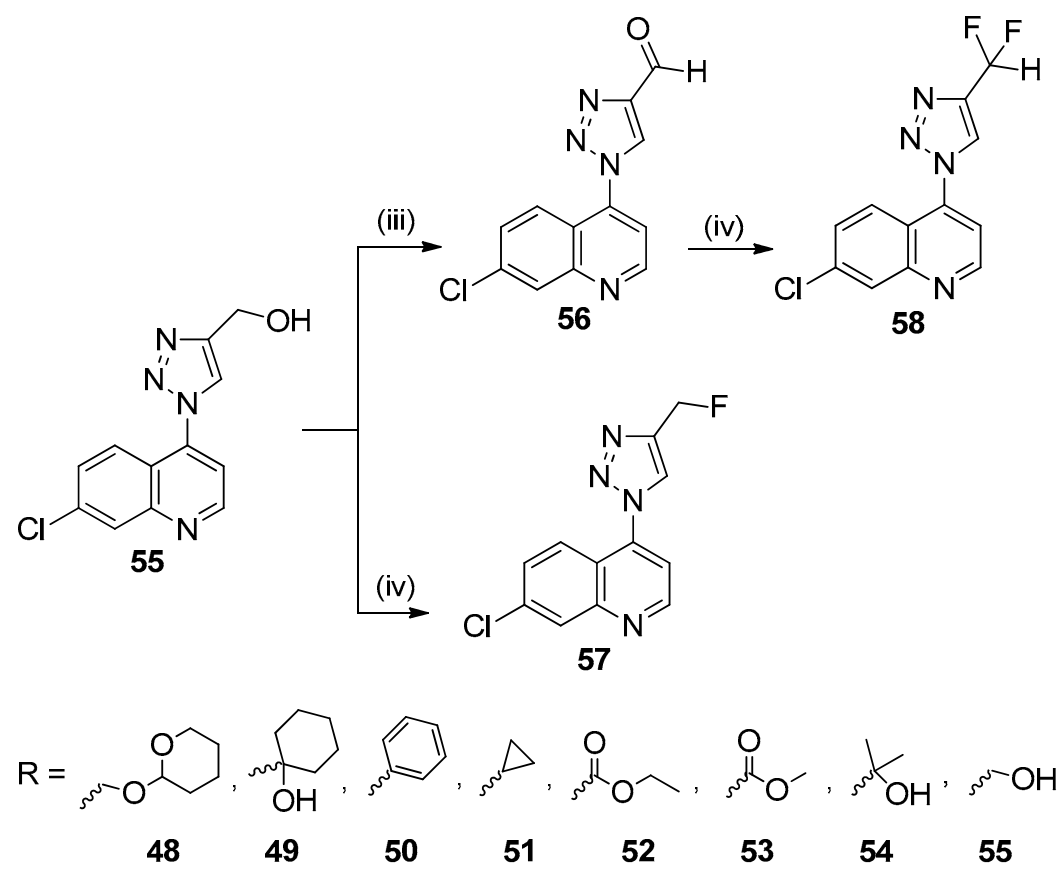

Figure 9. Synthesis of 7-chloro-4-(1H-1,2,3-triazol-1-yl)quinolines 48-58. Reagents and conditions: (i) $\mathrm{NaN}_{3}, \mathrm{MeOH}$, reflux, $24 \mathrm{~h}$; (ii) appropriate acetylene, L-ascorbic acid sodium salt, $\mathrm{CuSO}_{4} \cdot 5 \mathrm{H}_{2} \mathrm{O}$, $\mathrm{H}_{2} \mathrm{O} / \mathrm{t}-\mathrm{BuOH} / \mathrm{THF}$ (1:1:1), $25^{\circ} \mathrm{C}, 24 \mathrm{~h}$; (iii) $\mathrm{ClCOCOCl}, \mathrm{CH}_{2} \mathrm{Cl}_{2}$, DMSO, TEA, $-78^{\circ} \mathrm{C}, 6 \mathrm{~h}$; (iv) DAST, $\mathrm{CH}_{2} \mathrm{Cl}_{2}, 25^{\circ} \mathrm{C}, 24 \mathrm{~h}$.

The raw material 4,7-dichloroquinoline (59) was treated with sodium azide in $\mathrm{MeOH}$ under reflux for $24 \mathrm{~h}$ to obtain the 4-azido-7-chloroquinoline (60) derivative in 70\% yield. The 1,3-dipolar cycloaddition reaction between azide derivative 60 and the respective alkyne was performed with sodium ascorbate and a $\mathrm{Cu}(\mathrm{I})$ catalyst, in $\mathrm{H}_{2} \mathrm{O} / t$ - $\mathrm{BuOH} / \mathrm{THF}(1: 1: 1)$ at $25^{\circ} \mathrm{C}$ to obtain the 1 ,4-regioisomer of 7-chloro-4-(1H-1,2,3-triazol-1-yl)quinolines $48-58$ in $40-77 \%$ yield [38]. 
Alcohol derivative 55 was used for the synthesis of compounds 56, 57 and 58 . Aldehyde 56 was prepared in $55 \%$ yield, by the Swern oxidation of 55. The reaction of 55 with dimethylaminosulfur trifluoride (DAST) in $\mathrm{CH}_{2} \mathrm{Cl}_{2}$ at $25{ }^{\circ} \mathrm{C}$ for $24 \mathrm{~h}$ produced the monofluorinated derivative 57 in $70 \%$ yield. The difluorinated derivative 58 was obtained with $60 \%$ yield from the reaction of aldehyde 56 with DAST.

We synthesized eleven new hybrid 7-chloro-4-(1H-1,2,3-triazol-1-yl)quinolines 48-58. Six compounds, 48, 50-52, 56 and 58, exhibited in vitro activity against the P. falciparum W2 CQR clone, with $\mathrm{IC}_{50}$ values ranging from 1.4 to $46 \mu \mathrm{M}$. None of these compounds were toxic to HepG2 cells.

The most active compound 56 (Figure 10) contained an aldehyde group at the 4 position of $1 H$-1,2,3-triazol-1-yl, with an $\mathrm{IC}_{50}=1.4 \mu \mathrm{M}$ and $\mathrm{SI}=351$.<smiles>O=Cc1cn(-c2ccnc3cc(Cl)ccc23)nn1</smiles>

Figure 10. Structure of compound 56.

Hybrid antimalarial drugs have advantages over combined drugs since they decrease the risk of adverse drug-drug interactions and facilitate treatment adherence. Through a rational drug design approach, single hybrid molecules with dual functionality and/or targets have been planned and may have either the same mechanism of action as the precursor drugs or a distinct mechanism of action $[40,41]$.

A hybrid salt of artesunate and mefloquine, MEFAS (61) (Figure 11), was active against both the CQS 3D7 and CQR W2 strains of P. falciparum, with $\mathrm{IC}_{50}=0.001 \mu \mathrm{M}$. This hybrid salt was at least 5-fold more potent than mefloquine alone, more potent than artesunate against 3D7, as effective as artesunate against W2, and more potent than mixtures of the drugs. In vivo tests against $P$. berghei-infected mice, at a dose of $10 \mathrm{mg} / \mathrm{kg}$, led to cure without recrudescence of parasitemia. The in vivo cytotoxicity of MEFAS has demonstrated that its toxicity is 5-fold lower than that of mefloquine. The combined fixed dose of ASMQ (artesunate + mefloquine) was 3-fold more toxic than MEFAS [42]. MEFAS has been demonstrated to be an active blood schizonticidal and can also block the infectivity of $P$. falciparum gametocytes, 280- and 15-fold more effectively than mefloquine and artesunate alone, respectively [43]. These results make this compound very promising to target both the asexual parasites and gametocytes, improving the antimalarial effects.
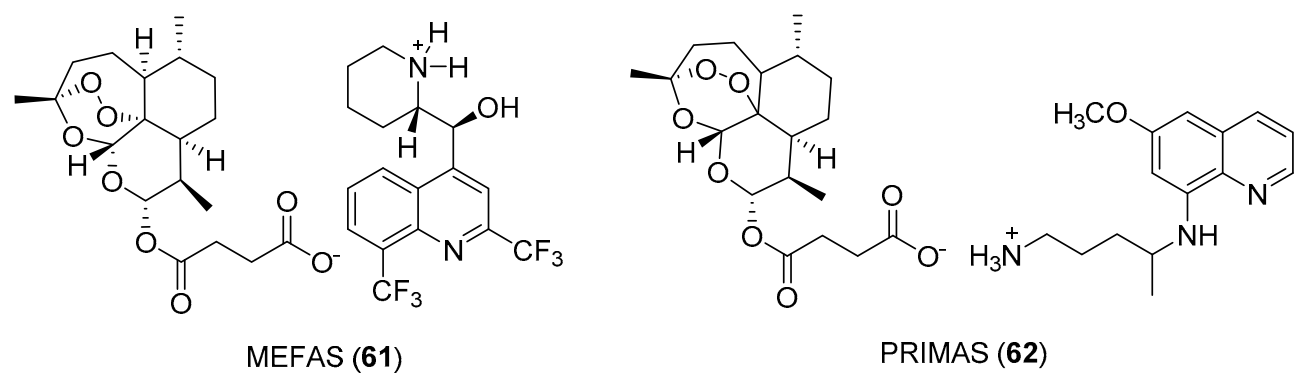

Figure 11. Structures of MEFAS and PRIMAS.

PRIMAS (62) (Figure 11) is also a hybrid salt between artesunate and primaquine under development by Boechat and coworkers [44]. This hybrid was designed with the goal of minimizing primaquine toxicity. Indeed, the PRIMAS hybrid salt is more active in vivo and in vitro and less toxic than primaquine. 
Hybrid compounds that have been designed through the incorporation of different pharmacophoric groups into the quinoline ring have generated effective derivatives. Some are already in the clinical trial phase [45].

In an effort to enhance the anti-P. falciparum activity of quinoline derivatives 63-77, a series of 15 molecules was designed from the precursor drugs chloroquine and sulfadoxine (Figure 12) [46]. These compounds contain the pharmacophore groups of a 7-chloroquinoline and arylsulfonamide, separated by a distinct linker that is not found in the individual drug molecular frameworks. The 7-chloroquinoline moiety was included because it is present in CQ, which is used to treat malaria, while the arylsulfonamide moiety is present in sulfadoxine. The pharmacophore groups were connected by a linker group containing $2-4 \mathrm{CH}_{2}$ units.<smiles>[R]c1ccc(S(=O)(=O)NCCNc2ccnc3cc(Cl)ccc23)cc1</smiles>

Figure 12. Rational approach to the design of compounds 63-77.

The synthetic route to prepare the $N$-(2-((7-chloroquinolin-4-yl)amino)alkyl)benzenesulfonamides 63-77 is shown in Figure 13.<smiles></smiles>

Figure 13. Synthetic route used to prepare compounds 63-77. Reagents and conditions: (i) appropriate diamine, reflux, $4 \mathrm{~h}$; (ii) appropriate sulfonyl chloride, $\mathrm{MeOH}, \mathrm{TEA}, 25^{\circ} \mathrm{C}, 24 \mathrm{~h}$.

The nucleophilic substitution reaction of 4,7-dichloroquinoline (59) with the corresponding diamine was performed to obtain intermediates $N^{1}$-(7-chloroquinolin-4-yl)alkyldiamine $\mathbf{7 8 - 8 0}$ in $85-90 \%$ yield [47]. The addition-elimination reaction between the $N^{1}$-(7-chloroquinolin-4-yl)alkyl-diamines 78-80 and the appropriate sulfonyl chloride in $\mathrm{MeOH}$ and TEA at $25{ }^{\circ} \mathrm{C}$ afforded the $N$-(2-((7-chloroquinolin-4-yl)amino)alkyl)benzenesulfonamides $63-77$ in $50-77 \%$ yield [48].

The 15 synthesized compounds 63-77 with different substituents at the 4 position of the arylsulfonamide group were tested against the W2 chloroquine and sulfadoxine-resistant $P$. falciparum clone and for their cytotoxicity.

All the compounds presented activity, and 10 of them showed $\mathrm{IC}_{50}$ values ranging from 0.05 to $0.40 \mu \mathrm{M}$ in the anti-HPR2 assay, which are lower than those of CQ and sulfadoxine, and none of them were toxic to BGM cells.

A direct relationship was observed between the increase in the number of methylene groups $\left(\mathrm{CH}_{2}\right)$ used as the linker and the increase in activity. Compounds with 4 and 3 methylene group $\left(\mathrm{CH}_{2}\right)$ linkers showed greater activity against $P$. falciparum than $\mathrm{CQ}$, while the series of compounds containing 2 methylene groups were less active than $\mathrm{CQ}$, with $\mathrm{IC}_{50}$ values in the range of 0.48 to $1.63 \mu \mathrm{M}$. Compounds 68-72, with three methylene groups as the linker, showed $\mathrm{IC}_{50}$ values ranging from 0.10 
to $0.35 \mu \mathrm{M}$. Compounds 74-77 containing four methylene groups as the linker were the most active of the series, with $\mathrm{IC}_{50}$ values ranging from $0.05-0.15 \mu \mathrm{M}$. Compound $73(\mathrm{R}=\mathrm{H})\left(\mathrm{IC}_{50}=0.40 \mu \mathrm{M}\right)$ was an exception. Compounds with substituents at the 4 position of the arylsulfonamide group increased the $P$. falciparum activity, while the derivatives without a substituent on the arylsulfonamide group were the least potent. Compounds $72\left(\mathrm{R}=\mathrm{F} ; \mathrm{IC}_{50}=0.10 \mu \mathrm{M}\right), 74\left(\mathrm{R}=\mathrm{CH}_{3} ; \mathrm{IC}_{50}=0.05 \mu \mathrm{M}\right), 75\left(\mathrm{R}=\mathrm{Cl} ; \mathrm{IC}_{50}\right.$ $=0.09 \mu \mathrm{M})$ and $77\left(\mathrm{R}=\mathrm{F} ; \mathrm{IC}_{50}=0.15 \mu \mathrm{M}\right)$ had the highest SI values: 3386.0, 2489.0, 1102.2 and 1031.3, respectively, so they were also evaluated for their antimalarial activity in $P$. berghei-infected mice.

Compounds 74 and 77 were partially active and inhibited P. berghei-parasitemia by $27 \%$ and 30\%, respectively on day 5 upon treatment at $10 \mathrm{mg} / \mathrm{kg}$, administered orally, whereas compounds 72 and 75 showed parasitemia inhibition at rates of $47 \%$ and $49 \%$, respectively.

Due to the advantages of the hybrids with the best results exhibited herein, compound 75 (Figure 14) was used as an antimalarial prototype (prototype II) to proceed with other studies to overcome the burden of resistance in P. falciparum.

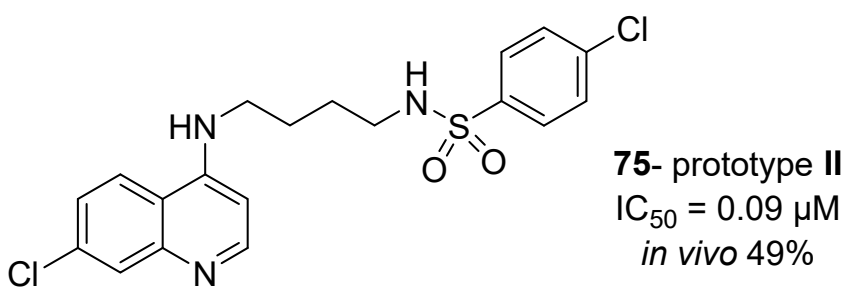

Figure 14. Structure of prototype II.

Continuing the search for new quinoline derivatives with antimalarial activity, a new class of hybrids 81-84 with atorvastatin (AVA) was planned inspired by prototype II [49]. The design of these molecules was based on the proven AVA antimalarial activity. The molecular hybridization of chloroquine derivatives 81-84 included the aminoquinoline moiety with the pyrrole of AVA. To connect these two pharmacophoric groups, the 7-chloroquinoline moiety was bound to the pentasubstituted pyrrole by a linker group containing $2-4 \mathrm{CH}_{2}$ units. Hybrid 84 was made by the direct attachment of primaquine to the pentasubstituted pyrrole (Figure 15).

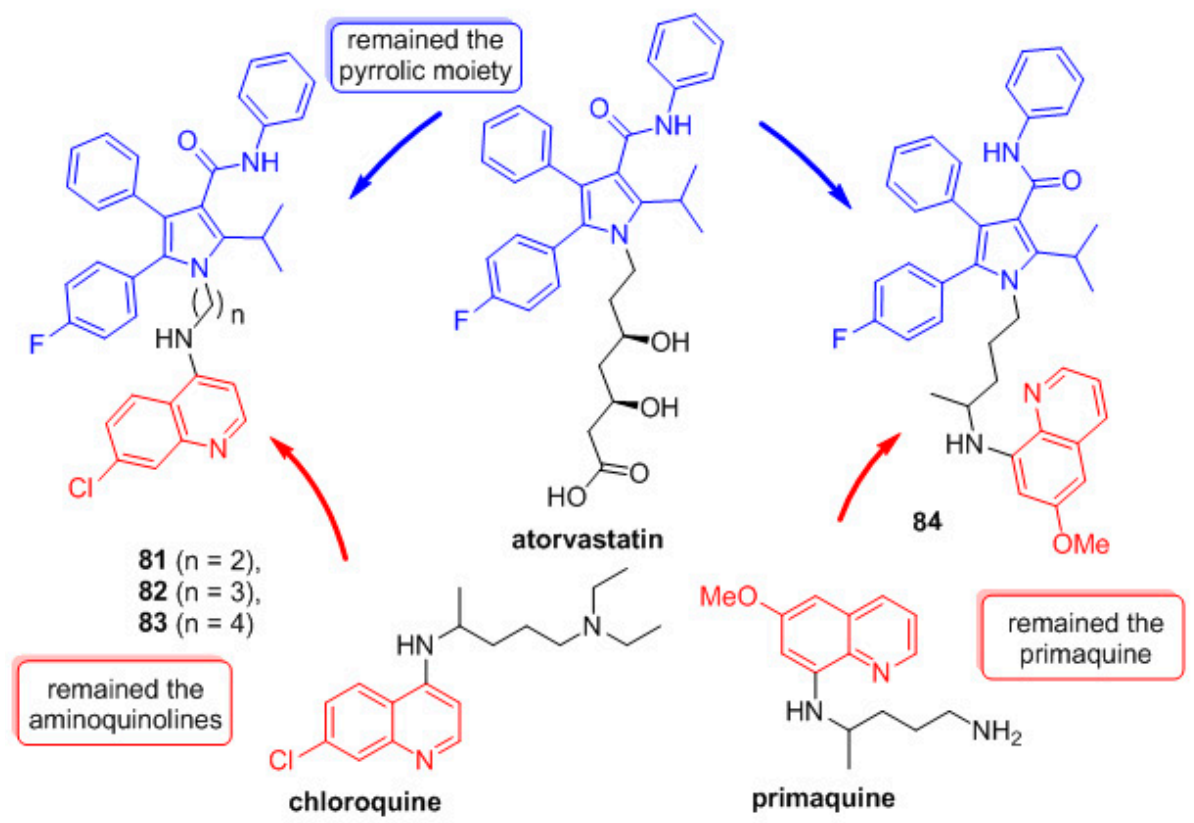

Figure 15. Rational approach to the design of compounds 81-84. 
The Paal-Knorr [50] reaction between the key intermediate used in prototype II synthesis [47] $\mathrm{N}$-(7-chloroquinolin-4-yl)alkyldiamines $\mathbf{7 8 - 8 0}$ or primaquine and 1,4-diketone 85, new pyrrole-chloroquine 81-83 and pyrrole-primaquine $\mathbf{8 4}$ derivatives were obtained, respectively, in $18-64 \%$ yield (Figure 16). The $N$-(7-chloroquinolin-4-yl)alkyldiamines 78-80 were obtained as previously described [46].
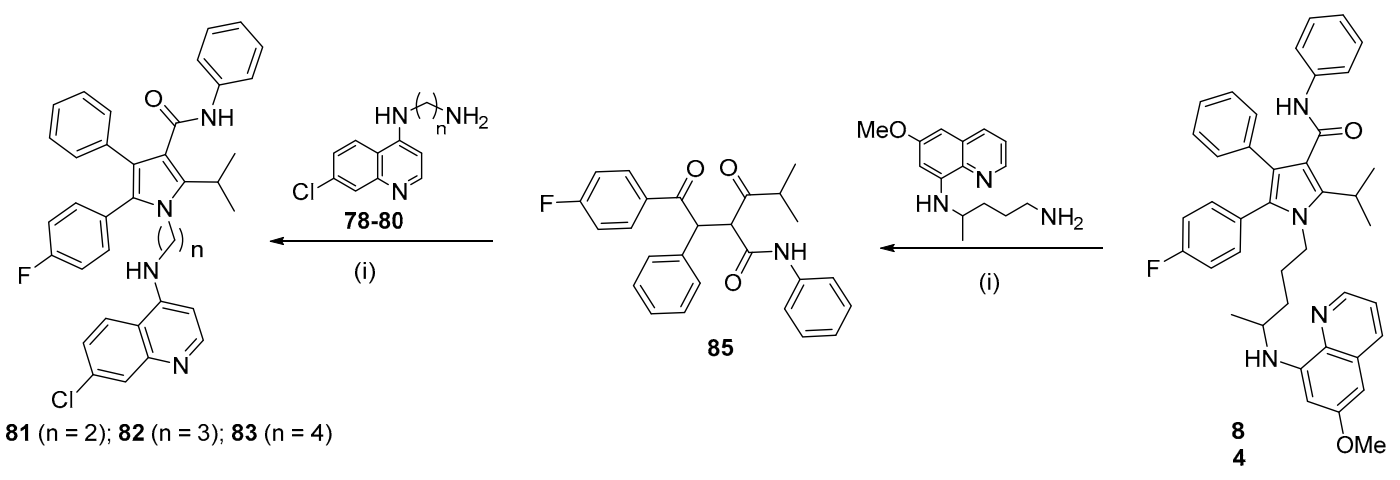

Figure 16. Synthetic route used to prepare compounds 81-84. Reagents and conditions: (i) pivalic acid, THF: cyclohexane, $80-100{ }^{\circ} \mathrm{C}, 18-64 \%$.

All compounds synthesized showed activity against the P. falciparum W2 clone, and none of them were significantly toxic to the BGM cell line. Chloroquine-AVA hybrids 81, 82 and 83 were the most active, with $\mathrm{IC}_{50}$ values of $0.99,0.65$ and $0.40 \mu \mathrm{M}$, respectively, which were in a similar range to chloroquine $\left(\mathrm{IC}_{50}=0.59 \mu \mathrm{M}\right)$, and all were better than primaquine $\left(\mathrm{IC}_{50}=1.89 \mu \mathrm{M}\right)$ and atorvastatin $\left(\mathrm{IC}_{50}=10.3 \mu \mathrm{M}\right)$, with good SI values. Herein, the activity of the compounds increased with the length of the carbon chain, which was similarly shown for the quinoline-sulfonamide derivatives that have four methylene groups as the linker. Compound $83(n=4)$ (Figure 17) exhibited better activity despite the exchange of the terminal amine for a polysubstituted pyrrole ring and was 26-fold more active than AVA. Primaquine derivative $84\left(\mathrm{IC}_{50}=1.41\right)$ was the least potent of the series. However, it was significantly less toxic and more active than primaquine and 7-fold more active than AVA $\left(\mathrm{IC}_{50}=10.3\right.$ $\mu \mathrm{M})$. This indicates that compound $\mathbf{8 4}$ is promising and may be a prototype in the search for a drug that is able to replace primaquine, because 84 was shown to be safer (SI > 1107) than primaquine (SI of 239). Additionally, to evaluate the importance of the pyrrolic moiety in the hybrid compounds, a pentasubstituted pyrrole without the aminoquinolinyl moiety was synthesized. This compound had no toxicity in vitro and was more potent $\left(\mathrm{IC}_{50}=6.39 \mu \mathrm{M}\right)$ than AVA. This result suggests that the pentasubstituted pyrrole might be the pharmacophoric group of AVA for antimalarial activity. New compounds containing pentasubstituted pyrrole-quinolines will be synthesized with the expectation of enhanced potency and solubility and will also be assayed for cerebral antimalarial activity to clarify the importance of AVA in this scaffold.

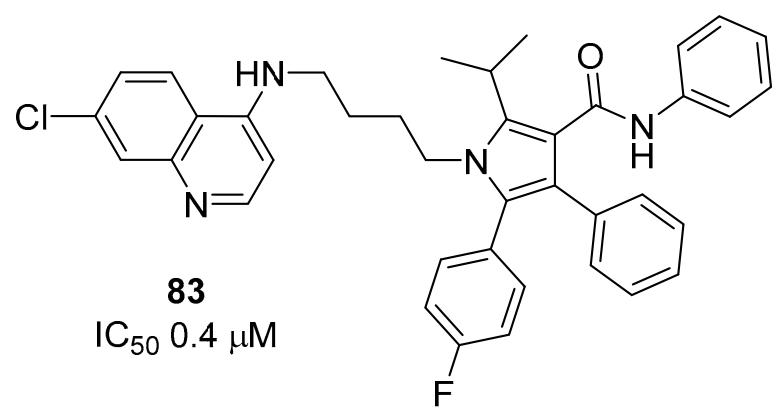

Figure 17. Structure of compound 83. 
In an effort to enhance the anti-P. falciparum activity of prototype II, new non-quinoline derivatives 86-95 were planned [51]. Therefore, the pyrazolopyridine system was selected as an isostere of quinoline, and the literature has demonstrated that this heterocycle possesses antimalarial activity [52]. The design of the non-quinoline derivatives consists of a ring isosterism in which the 7-chloroquinoline moiety is replaced by the 1-phenyl- $1 H$-pyrazolo[3,4- $b]$ pyridine system. An N-(4-aminobutyl)benzenesulfonamide group was attached to the 4 position of this heterocyclic ring. The $1 H$-pyrazolo[3,4- $b$ ]pyridine ring remains separated from the benzenesulfonamide moiety by the linker containing four methylene groups, which is similar to the linker found in the individual molecular framework of prototype II (Figure 18).

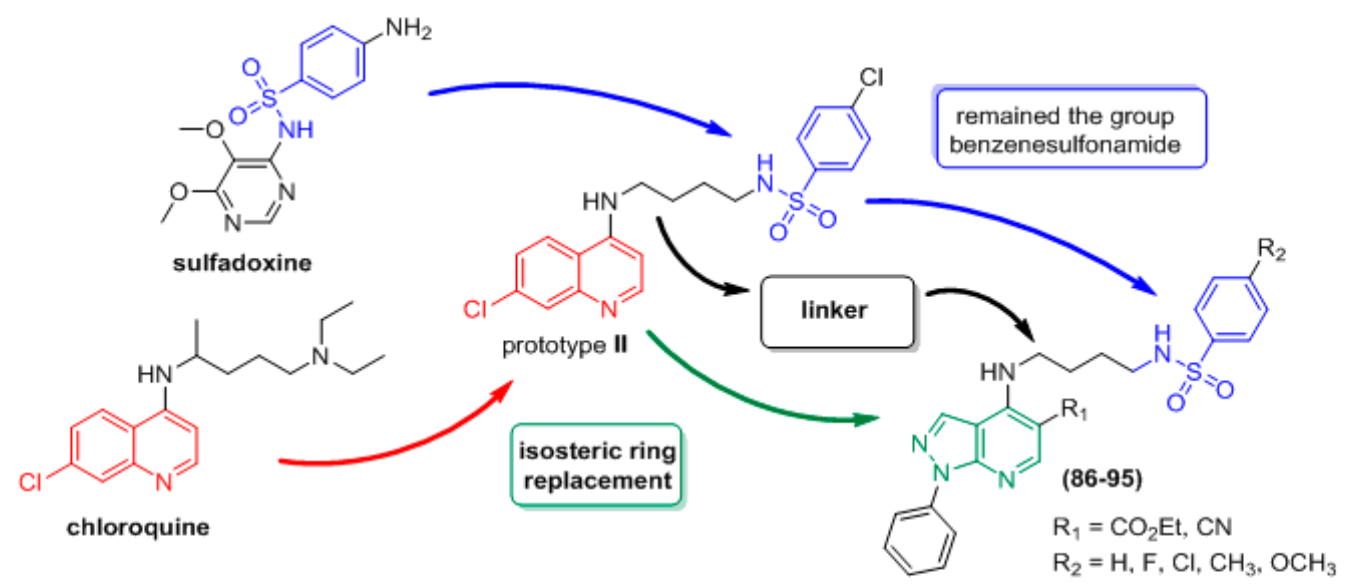

Figure 18. Rational approach to the design of compounds 86-95.

The synthetic route for preparing the $N-(4-((1-$ phenyl-1H-pyrazolo[3,4- $b]$ pyridin-4yl)amino)butyl)benzenesulfonamides 86-95 is shown in Figure 19.

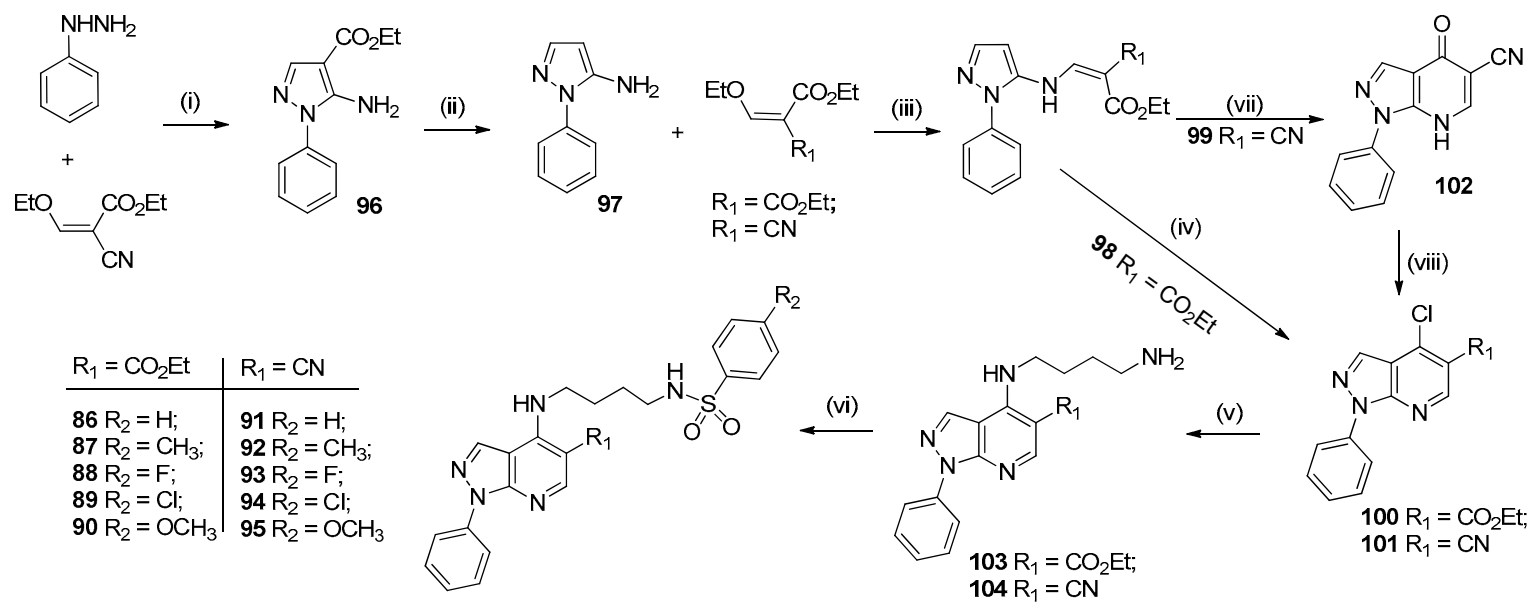

Figure 19. Synthetic route used to prepare compounds 86-95. Reagents and conditions: (i) EtOH, reflux, $1 \mathrm{~h}, 70 \%$; (ii) $\mathrm{H}_{3} \mathrm{PO}_{4}, 170{ }^{\circ} \mathrm{C}, 6 \mathrm{~h}, 86 \%$; (iii) $\mathrm{EtOH}$, reflux, $2 \mathrm{~h}, 86-88 \%$; (iv) $\mathrm{POCl}_{3}$, reflux, 6 h, 84\%; (v) butane-1,4-diamine, 1,4-dioxane, $25-80{ }^{\circ} \mathrm{C}, 1-4 \mathrm{~h}, 66-79 \%$; (vi) appropriate sulfonyl chloride, $\mathrm{MeOH}$, TEA, $25^{\circ} \mathrm{C}, 24 \mathrm{~h}, 59-70 \%$; (vii) Dowtherm, $250{ }^{\circ} \mathrm{C}, 40 \mathrm{~min}, 71 \%$; (viii) $\mathrm{POCl}_{3}$, reflux, $6 \mathrm{~h}, 90 \%$.

From the reaction of phenylhydrazine and ethyl 2-cyano-3-ethoxyacrylate, in ethanol under reflux, the ethyl 5-amino-1-phenyl-1H-pyrazole-4-carboxylate (96) was prepared at $70 \%$ yield. Hydrolysis followed by decarboxylation of this compound afforded 5-amino-1-phenyl- $1 \mathrm{H}$-pyrazol (97) in $86 \%$ yield. Michael addition of 97 with ethyl 2-cyano-3-ethoxyacrylate or diethyl 2-(ethoxymethylene)malonate in ethanol under reflux gave derivatives 98 and 99 in $86 \%$ and $88 \%$ yield, 
respectively. From the reaction of diethyl 2-(((1-phenyl-1H-pyrazol-5-yl)amino)methylene)malonate (98) with phosphorus oxychloride under reflux, the intermediate ethyl 4-chloro-1-phenyl-1H-pyrazolo[3,4- $b$ ]pyridine-5-carboxylate (100) was prepared in $84 \%$ yield [53]. However, the derivative 4-chloro-1-phenyl-1H-pyrazolo[3,4-b]pyridine-5-carbonitrile (101) could not be obtained using this methodology. To obtain 101, the cyclization of ethyl 2-cyano-3-((1-phenyl-1H-pyrazol-5-yl)amino)acrylate (99) was performed in refluxing Dowtherm for 40 min and 4-oxo-1-phenyl-4,7-dihydro- $1 H$-pyrazolo[3,4-b]pyridine-5-carbonitrile (102) was isolated by precipitation from hexane with a yield of $84 \%$ [20]. Derivative 102 was treated with phosphorus oxychloride to produce $\mathbf{1 0 1}$ in $90 \%$ yield. From the nucleophilic substitution reaction between 4-chloro-1-phenyl-1H-pyrazolo[3,4- $b$ ]pyridines 100 and 101 and butane-1,4-diamine, the intermediates ethyl 4-((4-aminobutyl)amino)-1-phenyl-1H-pyrazolo[3,4-b]pyridine-5-carboxylate (103) and 4-((4-aminobutyl)amino)-1-phenyl-1H-pyrazolo[3,4-b]pyridine-5-carbonitrile (104) were synthesized in $79 \%$ and $66 \%$ yield, respectively [54]. The addition-elimination reaction between the appropriate sulfonyl chloride and amines 103 and $\mathbf{1 0 4}$ was performed in $\mathrm{MeOH}$ and TEA $(1.0 \mathrm{mmol})$ at $25^{\circ} \mathrm{C}$ to obtain target compounds $N$-(4-((1-phenyl- $1 H$-pyrazolo[3,4-b]pyridin-4-yl)amino)butyl)benzenesulfonamides $\mathbf{8 6}-\mathbf{9 5}$ in $59-70 \%$ yield [46].

Ten derivatives of 1-phenyl-1H-pyrazolo[3,4-b]pyridine 86-95 were synthesized with different substituents at the 4 position of the benzenesulfonamide group and tested in vitro against the W2 chloroquine and sulfadoxine-resistant $P$. falciparum clone and for their cytotoxicity. All the compounds exhibited low toxicity to BGM cells and $\mathrm{IC}_{50}$ values lower than that of the control drug sulfadoxine $\left(\mathrm{IC}_{50}=15.0 \mu \mathrm{M}\right)$. However, the observed activity was lower than that of chloroquine $\left(\mathrm{IC}_{50}=0.55 \mu \mathrm{M}\right)$ and the quinoline-sulfonamide hybrid II.

The $\mathrm{IC}_{50}$ values ranged from 3.46 to $9.30 \mu \mathrm{M}$ in the anti-HPR2 assay. Derivative $\left(\mathrm{R}_{2}=\mathrm{CH}_{3}\right) 87$ with $\mathrm{IC}_{50}=3.46 \mu \mathrm{M}$, derivative $89\left(\mathrm{R}_{2}=\mathrm{Cl}\right)$ and $92\left(\mathrm{R}_{2}=\mathrm{CH}_{3}\right)$, both with $\mathrm{IC}_{50}$ values of $3.60 \mu \mathrm{M}$, were the most active against $P$. falciparum (Figure 20). Compound 89 also showed the highest SI value: $>277.77$.

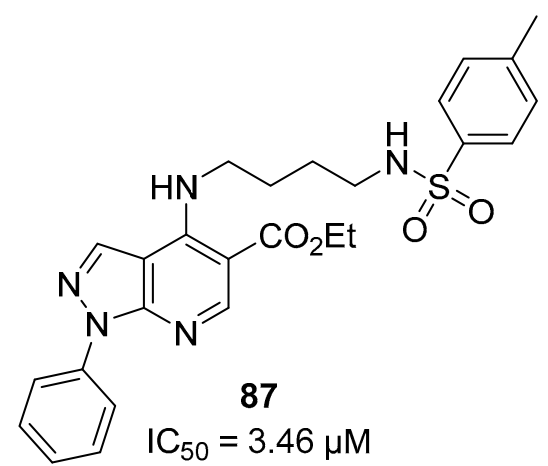

Figure 20. Structure of compound 87.

It was observed that the 3 compounds with $\mathrm{R}_{1}=\mathrm{CO}_{2} \mathrm{Et}$ at the 5 position of the $1 H$-pyrazolo[3,4-b]pyridine ring showed higher activity than those with $\mathrm{CN}$ at the same position.

Continuing the search to obtain new non-quinoline antimalarials, we used prototype II to design the new derivatives $N$-(4-((1-phenyl-1H-pyrazolo[3,4- $d$ ]pyrimidin-4-yl)amino)butyl)benzenesulfonamides 105-113 [55]. The 7-chloroquinoline moiety was replaced by the $1 H$-pyrazolo[3,4- $d$ ]pyrimidine system by ring isosterism, and at the 4 position of the heterocyclic ring, the $\mathrm{N}$-(4-aminobutyl)benzenesulfonamide moiety was attached, designing the $1 H$-pyrazolo[3,4-b]pyridine derivatives (Figure 21). 


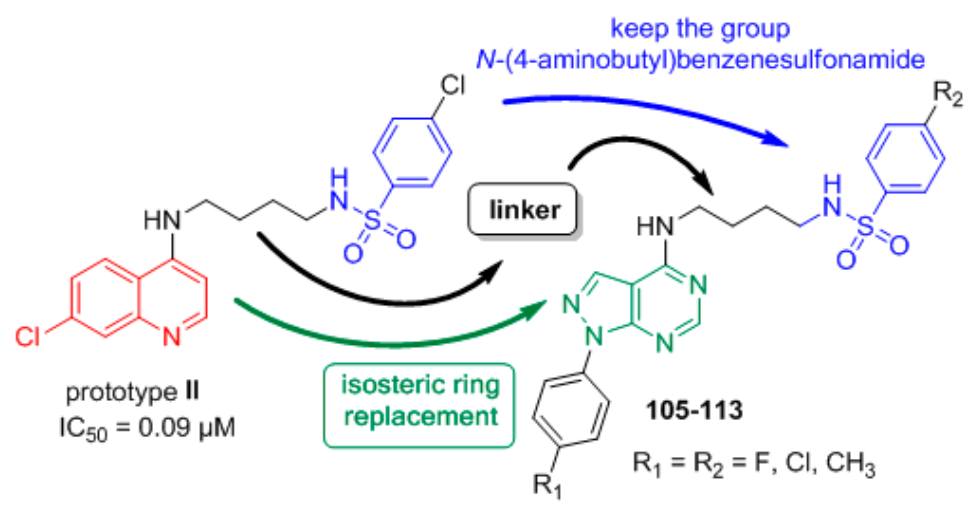

Figure 21. Rational approach to the design of compounds 105-113.

The synthetic route for preparing $N-(4-((1-$ phenyl-1H-pyrazolo[3,4- $d$ ]pyrimidin-4yl)amino)butyl)benzenesulfonamides 105-113 is shown in Figure 22.
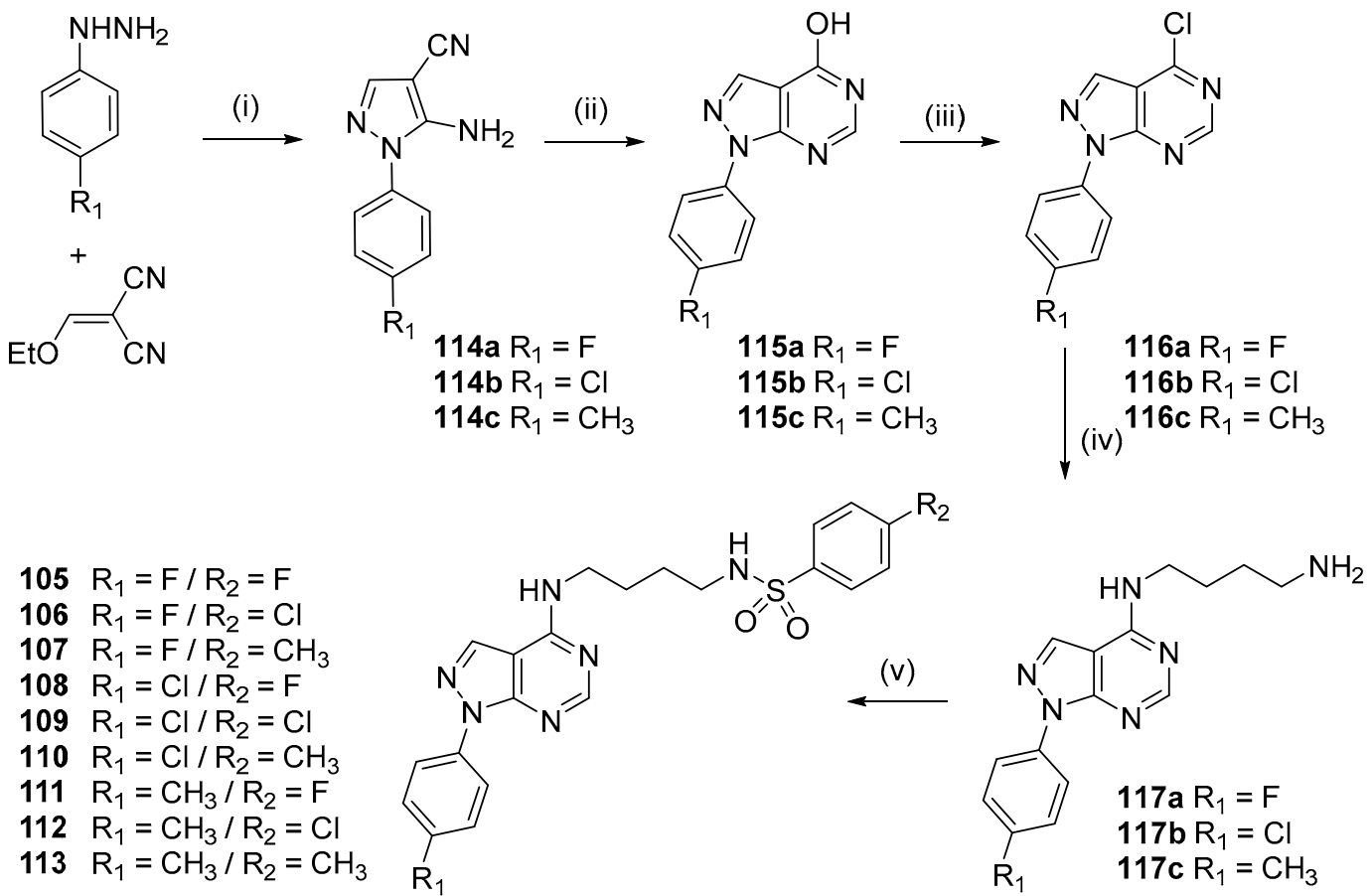

Figure 22. Synthetic route used to prepare compounds 105-113. Reagents and conditions: (i) EtOH, reflux, $2 \mathrm{~h}, 61-80 \%$; (ii) $\mathrm{HCOOH}$, reflux, 12 h, 73-89\%; (iii) $\mathrm{POCl}_{3}$, reflux, 24 h, 78-97\%; (iv) butane-1,4-diamine, $\mathrm{CH}_{3} \mathrm{CN}, 25{ }^{\circ} \mathrm{C}, 24 \mathrm{~h}, 23-36 \%$; (v) appropriate sulfonyl chloride, DMF, TEA, $90{ }^{\circ} \mathrm{C}, 24 \mathrm{~h}, 25-79 \%$.

The reaction of the appropriate phenylhydrazine and 2-(ethoxymethylene)malononitrile in ethanol under reflux for $2 \mathrm{~h}$ was performed to obtain the 5-amino-1-phenyl-1H-pyrazole-4-carbonitrile 114a-c compounds in $61-80 \%$ yield [56]. Reaction of the suitable 5-aminepyrazoles 114a-c and formic acid under reflux for $12 \mathrm{~h}$ afforded the 1-phenyl-1H-pyrazolo[3,4- $d$ ]pyrimidin-4-ols (115a-c) in 73-89\% yield [57]. Derivatives 115a-c were treated with phosphorus oxychloride under reflux for $24 \mathrm{~h}$ to produce 4-chloro-1-phenyl-1H-pyrazolo[3,4- $d$ ]pyrimidines (116a-c) in 78-97\% yield [51,54]. Nucleophilic substitution between 116a-c and butane-1,4-diamine in $\mathrm{CH}_{3} \mathrm{CN}$ at $25^{\circ} \mathrm{C}$ for $24 \mathrm{~h}$ was performed to obtain intermediates $N^{1}$-(1-phenyl-1H-pyrazolo[3,4- $d$ ]pyrimidin-4-yl)butane-1,4-diamines (117a-c) in $23-36 \%$ yield $[46,51]$. The addition-elimination reaction between diamines $\mathbf{1 1 7} \mathbf{a}-\mathbf{c}$ and the appropriate sulfonyl chloride in DMF and triethylamine (TEA) at $90{ }^{\circ} \mathrm{C}$ for $24 \mathrm{~h}$ afforded target compounds $N$-(4-((1-phenyl-1H-pyrazolo[3,4-d]pyrimidin-4-yl)amino)butyl)benzenesulfonamides (105-113) in 
$25-79 \%$ yield $[46,51]$. The nine derivatives of 1-phenyl- $1 H$-pyrazolo[3,4- $d]$ pyrimidine (105-113) that were synthesized were tested in vitro for their efficacy against the W2 chloroquine- and sulfadoxine-resistant $P$. falciparum clone and for their cytotoxicity. The anti-P. falciparum activities of the quinoline and $1 H$-pyrazolo[3,4-d]pyrimidine systems were then compared. Compounds 105-108, 111, and 113 showed $\mathrm{IC}_{50}$ values ranging from 5.13 to $43.40 \mu \mathrm{M}$ in the anti-HPR2 assay and low toxicity to BGM cells. Among the compounds (105-113) synthesized, six compounds exhibited anti-P. falciparum activity in vitro against chloroquine-resistant parasites, and none were toxic to BGM cells. This study showed that compound $107\left(\mathrm{R}_{1}=\mathrm{F} / \mathrm{R}_{2}=\mathrm{CH}_{3}\right)$ presented an $\mathrm{IC}_{50}$ value of $5.13 \mu \mathrm{M}$, which was lower than that of the control drug sulfadoxine $\left(\mathrm{IC}_{50}=15.00\right.$ $\mu \mathrm{M})$ in the anti-HRPII assay. In addition, most of the compounds in this series have higher SI values than sulfadoxine. However, the $1 H$-pyrazolo[3,4- $d]$ pyrimidine derivatives were not more potent than the control drug chloroquine $\left(\mathrm{IC}_{50}=0.55 \mu \mathrm{M}\right)$ and quinoline prototype II $\left(\mathrm{IC}_{50}=0.09 \mu \mathrm{M}\right)$. It is interesting to note that, similar to $1 H$-pyrazolo[3,4- $\left.d\right]$ pyridine 87 , the most active derivatives in this series have $\mathrm{CH}_{3}$ at the 4 position of the benzenesulfonamide moiety. Compounds $1 H$-pyrazolo[3,4- $d$ ] pyrimidine 107 and $1 H$-pyrazolo[3,4-b]pyridine 87 were equipotent; however, prototype II was still the most active (Figure 23). It is possible to conclude that the $1 H$-pyrazolo[3,4-d]pyrimidine and $1 H$-pyrazolo[3,4-b]pyridine systems are promising for further studies of their anti-P. falciparum activities.

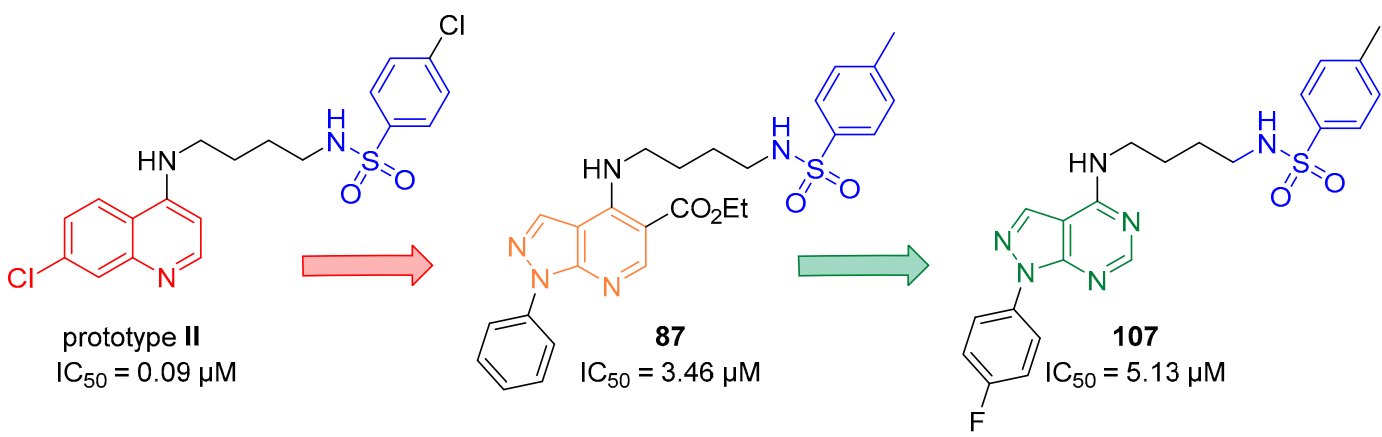

Figure 23. Comparison of prototype II with 87 and 107.

New mefloquine derivatives 118-133 were designed using molecular hybridization and ring bioisosterism. The pharmacophoric subunit 2,8-bis-(trifluoromethyl)quinoline, which is present in mefloquine, and the aminoaryl moiety of amodiaquine were linked to provide potent antimalarial drugs (Figure 24) [58]. The importance of the arylmethanol moiety in mefloquine, also present in quinine, is highly important for the antimalarial activity however, the arylmethanol moiety was replaced by phenylamino group present in amodiaquine. A variety of aliphatic, aromatic and heteroaromatic substituents were added to provide the electronic and lipophilic properties to research the contributions of each fragment to the activity profile of this new class of compounds. Compound $\mathbf{1 3 4}$ was also prepared to compare the importance of the 2,8-bis-(trifluoromethyl)quinoline moiety versus the 7-chloroquinoline moiety for antiplasmodial activity. 


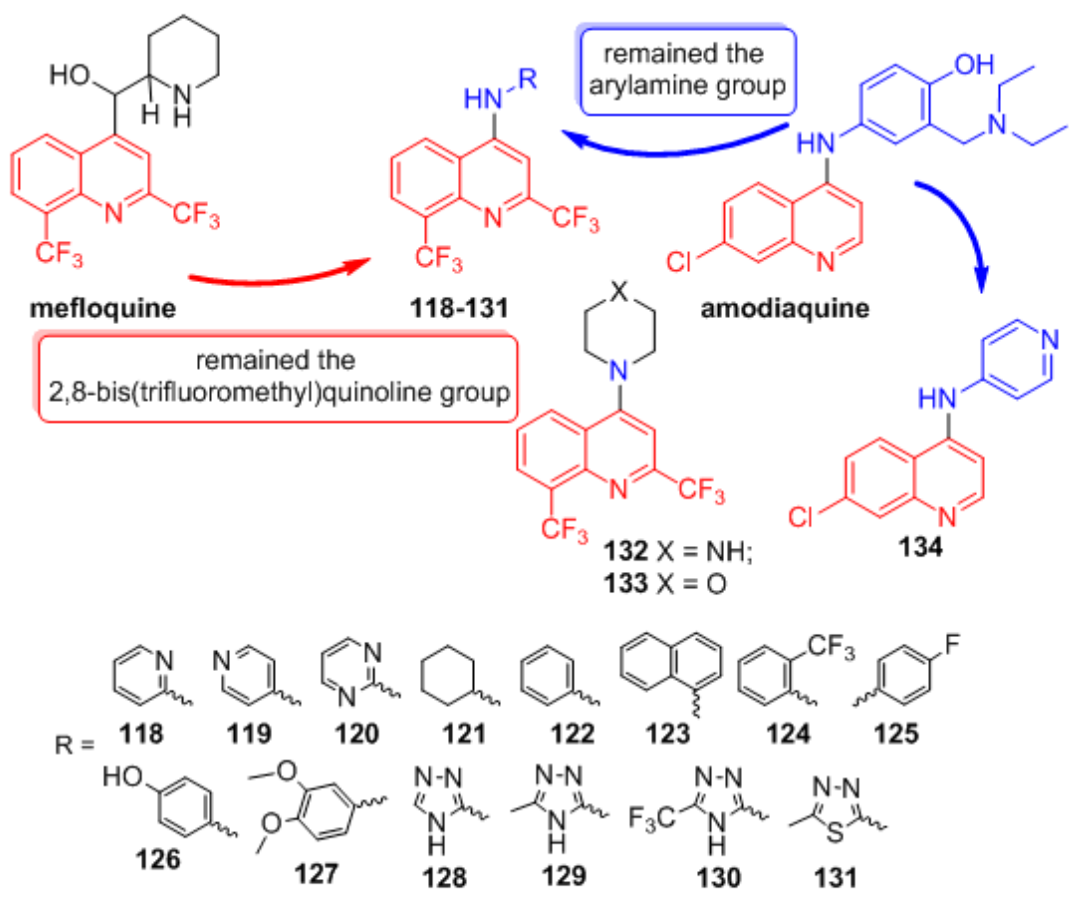

Figure 24. Rational approach to the design of compounds 118-134.

The synthetic route to prepare the $N$-substituted-2,8-bis(trifluoromethyl)-quinolin-4-amine derivatives 118-133 is shown in Figure 25. Reaction of 2-(trifluoromethyl)aniline with ethyl 4,4,4-trifluoroacetoacetate in polyphosphoric acid (PPA) for $3 \mathrm{~h}$ produced 2,8-bis(trifluoromethyl)quinolin-4-ol (135) in 91\% yield [59], which was then treated with phosphorus oxychloride at $80^{\circ} \mathrm{C}$ to obtain 4-chloro-2,8-bis(trifluoromethyl)quinoline (136) in 98\% yield [15].

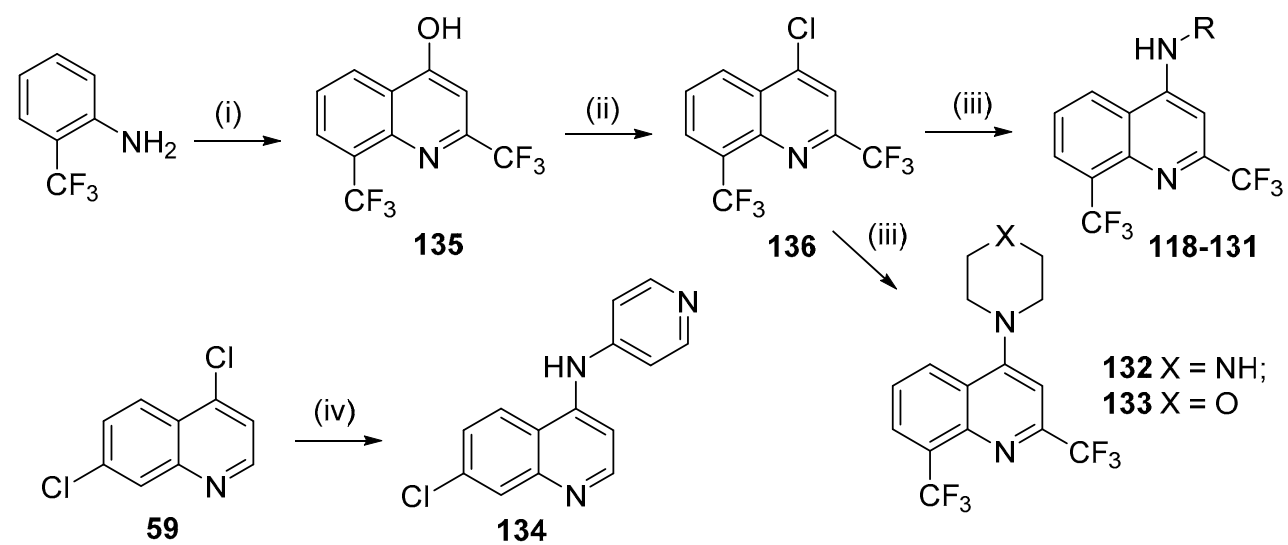

Figure 25. Synthetic route used to prepare compounds 118-134. Reagents and conditions: (i) ethyl 4,4,4-trifluoroacetoacetate, $\mathrm{PPA}, 150{ }^{\circ} \mathrm{C}, 3 \mathrm{~h}$; (ii) $\mathrm{POCl}_{3}, 80^{\circ} \mathrm{C}, 4 \mathrm{~h}$; (iii) appropriate amine, $\mathrm{NaH}, \mathrm{DMSO}$, $25^{\circ} \mathrm{C}, 1-24 \mathrm{~h}$; (v) pyridin-4-amine, EtOH, $25^{\circ} \mathrm{C}, 24 \mathrm{~h}$.

The nucleophilic aromatic substitution reaction of intermediates $\mathbf{1 3 6}$ with the appropriate amine

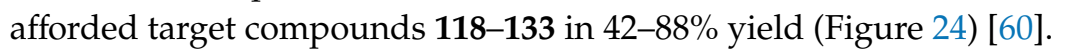

Compound 7-chloro- $N$-(pyridin-4-yl)quinolin-4-amine (134) was obtained from the reaction of pyridin-4-amine with the commercially available 4,7-dichloroquinoline (59) in 89\% yield [15].

First, a comparison was made between the importance of the 2,8-bis(trifluoromethyl)quinoline versus the 7-chloroquinoline moieties. Compounds $\mathbf{1 1 9}\left(\mathrm{IC}_{50}=8.4 \pm 1.7 \mu \mathrm{M}\right)$ and $\mathbf{1 3 4}\left(\mathrm{IC}_{50}=11.7 \pm 3\right.$ $\mu \mathrm{M})$ were equipotent, demonstrating that substitution of the quinoline core was not relevant for anti-P. falciparum activity. Compounds $\mathbf{1 3 2}\left(\mathrm{IC}_{50}=31.5 \mu \mathrm{M}\right)$ and $\mathbf{1 3 3}\left(\mathrm{IC}_{50}>143 \mu \mathrm{M}\right)$, which are both tertiary 
amines, were less active and inactive, respectively. This proves that the presence of the quinoline-NH group in this class of molecules is important. The reduction of anti-P. falciparum activity of $\mathbf{1 3 2}$ and 133 can be justified through the more rigid conformational structures of the cyclic tertiary amines compared to the arylamino derivatives. This rigidity interferes with the ability of the compounds to interact with the biomacromolecule receptor, although the $\mathrm{NH}$ group could still interact with the bioreceptor via hydrogen bonding. The most active compound $129\left(\mathrm{IC}_{50}=0.083 \mu \mathrm{M}\right)$ was 3-fold more potent than chloroquine $\left(\mathrm{IC}_{50}=0.25 \mu \mathrm{M}\right)$ (Figure 26). However, it was less active than mefloquine $\left(\mathrm{IC}_{50}=0.019 \mu \mathrm{M}\right)$. Moreover, as an advantage, its chemical structure is simpler than that of mefloquine because it does not contain a stereogenic center, and consequently, its synthesis in the laboratory is easier and less expensive. When the $\mathrm{CH}_{3}$ substituent was exchanged for $\mathrm{H}$ or $\mathrm{CF}_{3}$ on the triazole ring, as in $128\left(\mathrm{IC}_{50}=2.9 \mu \mathrm{M}\right)$ and $\mathbf{1 3 0}\left(\mathrm{IC}_{50}=11.5 \mu \mathrm{M}\right)$, respectively, significantly lower activities were observed. The isosteric replacement of the 5-methyltriazole unit in $\mathbf{1 2 9}$ with the 5-methylthiadiazole unit in $\mathbf{1 3 1}\left(\mathrm{IC}_{50}=1.8 \mu \mathrm{M}\right)$ decreased the activity, showing the importance of the triazole nucleus for anti-P. falciparum activity. Derivative $\mathbf{1 2 3}\left(\mathrm{IC}_{50}=9.6 \mu \mathrm{M}\right)$, with the amine $\beta$-naphthyl group, was three times more active than $122\left(\mathrm{IC}_{50}=28.0 \mu \mathrm{M}\right)$, with the amine phenyl group, showing the importance of lipophilicity in this region on biological activity; however, 123 was not selective and showed high toxicity. Aminepyridin-4-yl derivative $119\left(\mathrm{IC}_{50}=8.4 \mu \mathrm{M}\right)$ was 2.5 -fold more active and selective than aminepyridin-2-yl derivative $\mathbf{1 1 8}\left(\mathrm{IC}_{50}=19.6 \mu \mathrm{M}\right)$. Moreover, when we evaluated the effect of the aminepyrimidin-2-yl derivative $\mathbf{1 2 0}\left(\mathrm{IC}_{50}=8.4 \mu \mathrm{M}\right)$, it showed equipotent anti-P. falciparum activity and the same toxicity as $\mathbf{1 1 9 .}$

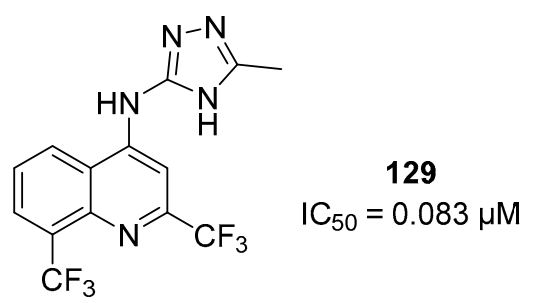

Figure 26. Structure of compound 129.

\section{Conclusions}

During our research on new drugs for malaria treatment, we sought out medicinal chemistry to make structural modifications and hybridizations to obtain new compounds that are more selective and less toxic. In the search of non-quinolinic compounds, a series of $[1,2,4]$ triazolo[1,5-a]pyrimidine derivatives were designed. These compounds exhibited anti-P. falciparum activities, and none of the compounds were toxic to HepG2 cells. Compound 2, with the $\mathrm{CF}_{3}$ group at the 2 position and $\beta$-naphthylamine at the 7 position, was the most active, and it has an important contribution to anti- $P$. falciparum activity with $\mathrm{IC}_{50}=0.023 \mu \mathrm{M}$. Derivative 2 was used as a prototype compound (prototype I) for future investigations in the search for compounds for the treatment of malaria. Bioisosteric replacements of the triazolo[ $1,5-a]$ pyrimidine ring on prototype $\mathbf{I}$ by the pyrazolo[1,5- $a]$ pyrimidine ring were shown to be effective. Derivatives with $\beta$-naphthylamine at the 7 position were the most active. Compounds $33\left(\mathrm{R}_{1}=\mathrm{CF}_{3}, \mathrm{R}_{2}=\mathrm{CH}_{3}\right)$ and $38\left(\mathrm{R}_{1}=\mathrm{CH}_{3}, \mathrm{R}_{2}=\mathrm{CH}_{3}\right)$ exhibited low toxicity and the low $\mathrm{IC}_{50}$ values of 1.2 and $5.1 \mu \mathrm{M}$, respectively, and consequently the highest SI values of 467.8 and 79.6, respectively. These compounds showed a 50\% reduction of parasitemia in the in vivo anti- $P$. berghei malaria evaluation. Compound $44\left(\mathrm{R}_{1}=\mathrm{CH}_{3}, \mathrm{R}_{2}=\mathrm{CF}_{3}\right)$ showed the best inhibition of the enzyme $P f \mathrm{DHODH}$ with an $\mathrm{IC}_{50}=0.16 \mu \mathrm{M}$, which was more potent than prototype $\mathbf{I}\left(\mathrm{IC}_{50}=0.70 \mu \mathrm{M}\right)$.

A hybrid salt of artesunate and mefloquine, MEFAS (61), has been demonstrated to be 280- and 15-fold more effective than both mefloquine and artesunate alone, respectively, against $P$. falciparum gametocytes. Against P. berghei-infected mice, a dose of $10 \mathrm{mg} / \mathrm{kg}$ led to cure, and the toxicity of $\mathbf{6 1}$ was 5-fold lower than that of mefloquine. PRIMAS (62) is also a hybrid salt between artesunate and primaquine. This hybrid salt is more active in vivo and in vitro and less toxic than primaquine. 
The 1,2,3-triazol-1-yl quinoline derivatives exhibited activity in vitro against the P. falciparum W2 CQR clone without toxicity to HepG2 cells. The most active compound 56 showed an $\mathrm{IC}_{50}$ $=1.4 \mu \mathrm{M}$, and $\mathrm{SI}=351$. Compound $75\left(\mathrm{R}=\mathrm{Cl} ; \mathrm{IC}_{50}=0.09 \mu \mathrm{M}\right)$ had an SI value of 1102.2 and was evaluated for its antimalarial activity in P. berghei-infected mice, showing $49 \%$ inhibition of parasitemia. This compound was used as an antimalarial prototype (prototype II) to proceed with other studies to overcome the burden of resistance in P. falciparum. From prototype II, derivatives $1 H$-pyrazolo[3,4- $d$ ]pyrimidine and $1 H$-pyrazolo[3,4- $b$ ]pyridine were designed. These cores were active against $P$. falciparum with 87 giving an $\mathrm{IC}_{50}=3.46 \mu \mathrm{M}$ and 107 showing an $\mathrm{IC}_{50}=5.13 \mu \mathrm{M}$, which were lower than that of the control drug sulfadoxine; however, prototype II was still the most active. Chloroquine/primaquine-atorvastatin (AVA) hybrids showed similar activity to chloroquine but were better than primaquine. The primaquine derivative was significantly less toxic and more active than primaquine, 7-fold more active than AVA and was shown to be safer (SI > 1107) than primaquine (SI of 239). The 2,8-bis-(trifluoromethyl)quinoline derivatives are chemical structures simpler than those of mefloquine. Compound 129, the most active compound, showed an $\mathrm{IC}_{50}=0.083 \mu \mathrm{M}$ and was 3-fold more potent than chloroquine $\left(\mathrm{IC}_{50}=0.25 \mu \mathrm{M}\right)$. We can conclude that these compounds are promising for further studies of antimalarial. However, the antimalarial activity of promising compounds to reverse artemisinin resistance can only be seen by establishing the ring-stage survival assay (RSA) [61].

Author Contributions: L.C.S.P., L.M.F., M.O.G. and F.F.S. wrote the manuscript; N.B. reviewed the manuscript.

Funding: This study was financed in part by the Coordenação de Aperfeiçoamento de Pessoal de Nível Superior-Brasil (CAPES)-Finance Code 001 and PROEP/CNPQ-FAR/FIOCRUZ 407853/2017-0.

Acknowledgments: The authors thank the Coordination of Improvement of Higher Education (CAPES) and the National Council of R\&D of Brazil (CNPq) for the fellowships granted to the authors. We also thank the Foundation for Research of the State of Rio de Janeiro (FAPERJ), Technological Development Program on Products for Health (PDTIS), for financial support. L.C.S.P. and N.B. are recipients of research productivity fellowships from the CNPq and N.B. from FAPERJ ("Cientista do Nosso Estado").

Conflicts of Interest: The authors declare no conflict of interest.

\section{References}

1. World Health Organization (WHO). World Malaria Report. Available online: https://apps.who.int/iris/ bitstream/handle/10665/275867/9789241565653-eng.pdf?ua=1 (accessed on 6 July 2019).

2. World Health Organization (WHO). Guidelines for the Treatment of Malaria. 3rd ed.; Available online: http://www.who.int/malaria/publications/atoz/9789241549127/en/ (accessed on 6 July 2019).

3. Hott, A.; Tucker, M.S.; Casandra, D.; Sparks, K.; Kyle, D.E. Fitness of artemisinin-resistant Plasmodium falciparum in vitro. J. Antimicrob. Chemother. 2015, 70, 2787-2796. [CrossRef] [PubMed]

4. Mbengue, A.; Bhattacharjee, S.; Pandharkar, T.; Liu, H.; Estiu, G.; Stahelin, R.V.; Rizk, S.S.; Njimoh, D.L.; Ryan, Y.; Chotivanich, K.; et al. A molecular mechanism of artemisinin resistance in Plasmodium falciparum malaria. Nature 2015, 520, 683-687. [CrossRef] [PubMed]

5. Ding, X.C.; Ubben, D.; Wells, T.N.C. A framework for assessing the risk of resistance for anti-malarials in development. Malaria J. 2012, 11, 292. [CrossRef] [PubMed]

6. Naß, J.; Efferth, T. Development of artemisinin resistance in malaria therapy. Pharmacol. Res. 2019, 146, 104275. [CrossRef]

7. Anthony, M.P.; Burrows, J.N.; Duparc, S.; Moehrle, J.J.; Wells, T.N.C. The global pipeline of new medicines for the control and elimination of malaria. Malaria J. 2012, 11, 316. [CrossRef]

8. Alven, S.; Aderibigbe, B. Combination Therapy Strategies for the Treatment of Malaria. Molecules 2019, 24, 3601. [CrossRef]

9. Xhamla Nqoro, X.; Naki Tobeka, N.; Aderibigbe, B.A. Quinoline-Based Hybrid Compounds with Antimalarial Activity. Molecules 2017, 22, 2268. [CrossRef]

10. Medicines for Malaria Venture (MMV). Global Portfolio of Antimalarial Medicines. Available online: https://www.mmv.org/research-development/mmv-supported-projects (accessed on 6 July 2019).

11. Narula, A.K.; Azad, C.S.; Nainwal, L.M. New dimensions in the field of antimalarial research against malaria resurgence. Eur. J. Med. Chem. 2019, 181, 111353. [CrossRef] 
12. Marella, A.; Verma, G.; Shaquiquzzaman, M.D.; Khan, M.D.F.; Akhtar, W.; Alam, M.D.M. Malaria Hybrids: A Chronological Evolution. Mini-Rev. Med. Chem. 2019, 19, 1144-1177. [CrossRef]

13. Wamae, K.; Okanda, D.; Ndwiga, L.; Osoti, V.; Kimenyi, K.M.; Abdi, A.I.; Bejon, P.; Sutherland, C.; Ochola-Oyier, L.I. No evidence of P. falciparum K13 artemisinin conferring mutations over a 24-year analysis in Coastal Kenya, but a near complete reversion to chloroquine wild type parasites. Antimicrob. Agents Chemother. 2010, 45, 3245-3264. [CrossRef]

14. Wells, T.N.; Hooft van Huijsduijnen, R.; Van Voorhis, W.C. Malaria medicines: A glass half full? Nat. Rev. Drug Discov. 2015, 14, 424-442. [CrossRef]

15. Boechat, N.; Pinheiro, L.C.S.; Silva, T.S.; Aguiar, A.C.C.; Carvalho, A.S.; Bastos, M.M.; Costa, C.C.P.; Pinheiro, S.; Pinto, A.C.; Mendonça, J.S.; et al. New Trifluoromethyl Triazolopyrimidines as Anti-Plasmodium falciparum Agents. Molecules 2012, 17, 8285-8302. [CrossRef]

16. Kirk, K.L. Fluorination in medicinal chemistry: Methods, strategies, and recent developments. Org. Process. Res. Dev. 2008, 12, 305-321. [CrossRef]

17. Purser, S.; Moore, P.R.; Swallow, S.; Gouverneur, V. Fluorine in medicinal chemistry. Chem. Soc. Rev. 2008, 37, 320-330. [CrossRef]

18. Boechat, N.; Bastos, M.M. Trifluoromethylation of carbonyl compounds. Curr. Org. Synth. 2010, 7, 403-413. [CrossRef]

19. Zohdi, H.F. Reactions with 3-amino-5-(trifluoromethyl)-1,2,4-triazole: A simple route to fluorinated polysubstituted triazolo[1,5-a]pyrimidine and triazolo[5,1-c]triazine derivatives. J. Chem. Res. (S) 1997, 392-393. [CrossRef]

20. Leal, B.; Afonso, I.F.; Rodrigues, C.R.; Abreu, P.A.; Garrett, R.; Pinheiro, L.C.S.; Azevedo, A.R.; Borges, J.C.; Vegi, P.F.; Santos, C.C.C.; et al. Antibacterial profile against drug-resistant Staphylococcus epidermidis clinical strain and structure-activity relationship studies of $1 \mathrm{H}-$ pyrazolo[3,4-b]pyridine and thieno[2,3-b]pyridine derivatives. Bioorg. Med. Chem. 2008, 16, 8196-8204. [CrossRef]

21. Pinheiro, M.P.; Iulek, J.; Nonato, M.C. Crystal structure of Trypanosoma cruzi dihydroorotate dehydrogenase from Y strain. Biochem. Biophys. Res. Commun. 2008, 369, 812-817. [CrossRef]

22. Hoelz, L.V.B.; Calil, F.A.; Nonato, M.C.; Pinheiro, L.C.S.; Boechat, N. Plasmodium falciparum dihydroorotate dehydrogenase: A drug target against malaria. Future Med. Chem. 2018, 10, 1853-1874. [CrossRef]

23. Phillips, M.A.; Gujjar, R.; Malmquist, N.A.; White, J.; El Mazouni, F.; Baldwin, J.; Rathod, P.K. Triazolopyrimidine-based dihydroorotate dehydrogenase inhibitors with potent and selective activity against the malaria parasite Plasmodium falciparum. J. Med. Chem. 2008, 51, 3649-3653. [CrossRef]

24. Gujjar, R.; El Mazouni, F.; White, K.L.; White, J.; Creason, S.; Shackleford, D.M.; Deng, X.; Charman, W.N.; Bathurst, I.; Burrows, J.; et al. Lead optimization of aryl and aralkyl amine-based triazolopyrimidine inhibitors of Plasmodium falciparum dihydroorotate dehydrogenase with antimalarial activity in mice. J. Med. Chem. 2011, 54, 3935-3949. [CrossRef] [PubMed]

25. Phillips, M.A.; White, K.L.; Kokkonda, S.; Deng, X.; White, J.; El Mazouni, F.; Marsh, K.; Tomchick, D.R.; Manjalanagara, K.; Rudra, K.R.; et al. A triazolopyrimidine-based dihydroorotate dehydrogenase inhibitor with improved drug-like properties for treatment and prevention of malaria. ACS Infect. Dis. 2016, 2, 945-957. [CrossRef]

26. Pavadai, E.; El Mazouni, F.; Wittlin, S.; de Kock, C.; Phillips, M.A.; Chibale, K. Identification of new human malaria parasite Plasmodium falciparum dihydroorotate dehydrogenase inhibitors by pharmacophore and structure-based virtual screening. J. Chem. Inf. Model. 2016, 56, 548-562. [CrossRef] [PubMed]

27. Azeredo, L.F.S.P.; Coutinho, J.P.; Jabor, V.A.P.; Feliciano, P.R.; Nonato, M.C.; Kaiser, C.R.; Menezes, C.M.S.; Hammes, A.S.O.; Caffarena, E.R.; Hoelz, L.V.B.; et al. Evaluation of 7-arylaminopyrazolo[1,5-a]pyrimidines as anti-Plasmodium falciparum, antimalarial, and $P f$-dihydroorotate dehydrogenase inhibitors. Eur. J. Med. Chem. 2017, 126, 72-83. [CrossRef] [PubMed]

28. Wu, T.; Nagle, A.S.; Chatterjee, A.K. Road towards new antimalarials-Overview of the strategies and their chemical progress. Curr. Med. Chem. 2011, 18, 853-871. [CrossRef]

29. Kaur, K.; Jain, M.; Reddy, R.P.; Jain, R. Quinolines and structurally related heterocycles as antimalarials. Eur. J. Med. Chem. 2010, 45, 3245-3264. [CrossRef]

30. Mushtaque, M.D. Shahjahan Reemergence of chloroquine (CQ) analogs as multi-targeting antimalarial agents: A review. Eur. J. Med. Chem. 2015, 90, 280-295. [CrossRef] 
31. Singh, K.; Kaur, H.; Smith, P.; de Kock, C.; Chibale, K.; Balzarini, J. Quinoline-pyrimidine hybrids: Synthesis, antiplasmodial activity, SAR, and mode of action studies. J. Med. Chem. 2014, 57, 435-448. [CrossRef]

32. Singh, K.; Kaur, H.; Chibale, K.; Balzarini, J. Synthesis of 4-aminoquinoline-pyrimidine hybrids as potent antimalarials and their mode of action studies. Eur. J. Med. Chem. 2013, 66, 314-323. [CrossRef]

33. Singh, K.; Kaur, H.; Chibale, K.; Balzarini, J.; Little, S.; Bharatam, P.V. 2-Aminopyrimidine based 4-aminoquinoline anti-plasmodial agents. Synthesis, biological activity, structure-activity relationship and mode of action studies. Eur. J. Med. Chem. 2012, 52, 82-97. [CrossRef]

34. Vandekerckhove, S.; D'hooghe, M. Quinoline-based antimalarial hybrid compounds. Bioorg. Med. Chem. 2015, 23, 5098-5119. [CrossRef] [PubMed]

35. Kalaria, P.N.; Karad, S.C.; Raval, D.K. A review on diverse heterocyclic compounds as the privileged scaffolds in antimalarial drug discovery. Eur. J. Med. Chem. 2018, 158, 917-936. [CrossRef] [PubMed]

36. Boechat, N.; Ferreira, M.L.G.; Pinheiro, L.C.S.; Jesus, A.M.L.; Leite, M.M.M.; Aguiar, A.C.C.; Andrade, I.M.; Krettli, A.U. New compounds hybrids $1 \mathrm{H}-1,2,3$-triazole-quinoline against Plasmodium falciparum. Chem. Biol. Drug. Des. 2014, 84, 325-332. [CrossRef] [PubMed]

37. Bakunov, S.A.; Bakunova, S.M.; Wenzler, T.; Ghebru, M.; Werbovetz, K.A.; Brun, R.; Tidwell, R.R. Synthesis and antiprotozoal activity of cationic 1,4-Diphenyl-1H-1,2,3-triazoles. J. Med. Chem. 2010, 53, 254-272. [CrossRef]

38. Boechat, N.; Ferreira, V.F.; Ferreira, S.B.; Ferreira, M.L.G.; Silva, F.C.; Bastos, M.M.; Costa, M.S.; Lourenço, M.C.; Pinto, A.C.; Krettli, A.U.; et al. Novel 1,2,3-triazole derivatives for use against Mycobacterium tuberculosis H37Rv (ATCC 27294) strain. J. Med. Chem. 2011, 54, 5988-5999. [CrossRef]

39. Ferreira, S.B.; Costa, M.S.; Boechat, N.; Bezerra, S.R.J.; Genestra, M.S.; Canto-Cavalheiro, M.M.; Kover, W.B.; Ferreira, V.F. Synthesis and evaluation of new difluoromethyl azoles as antileishmanial agents. Eur. J. Med. Chem. 2007, 42, 1388-1395. [CrossRef]

40. Muregi, F.W.; Ishih, A. Next-Generation antimalarial drugs: Hybrid molecules as a new strategy in drug design. Drug. Dev. Res. 2010, 71, 20-32. [CrossRef]

41. Morphy, R.; Rankovic, Z. Designed multiple ligands. An emerging drug discovery paradigm. J. Med. Chem. 2005, 48, 6523-6543. [CrossRef]

42. de Pilla Varotti, F.; Botelho, A.C.C.; Andrade, A.A.; de Paula, R.C.; Fagundes, E.M.; Valverde, A.; Mayer, L.M.; Mendonça, J.S.; de Souza, M.V.; Boechat, N.; et al. Synthesis, antimalarial activity, and intracellular targets of Mefas, a new hybrid compound derived from mefloquine and artesunate. Antimicrob. Agents Chemother. 2008, 52, 3868-3874. [CrossRef]

43. Penna-Coutinho, J.; Almela, M.J.; Miguel-Blanco, C.; Herreros, E.; Sá, P.M.; Boechat, N.; Krettli, A.U. Transmission-blocking potential of MEFAS, a hybrid compound derived fromartesunate and mefloquine. Antimicrob. Agents Chemother. 2016, 60, 3145-3147. [CrossRef]

44. Boechat, N.; Souza, M.V.N.; Valverde, A.L.; Krettli, A.U. Compounds derived from artesunate, preparation process, pharmaceutical composition and use of the respective medicine. U.S. Patent 8,802,701 B2, 12 August 2014.

45. Teixeira, C.; Vale, N.; Pérez, B.; Gomes, A.; Gomes, J.R.B.; Gomes, P. “Recycling” classical drugs for malaria. Chem. Rev. 2014, 114, 11164-11220. [CrossRef] [PubMed]

46. Pinheiro, L.C.S.; Boechat, N.; Ferreira, M.L.G.; Junior, C.C.S.; Jesus, A.M.L.; Leite, M.M.M.; Souza, N.; Krettli, A.U. Anti-Plasmodium falciparum activity of quinoline-sulfonamide hybrids. Bioorg. Med. Chem. 2015, 23, 5979-5984. [CrossRef] [PubMed]

47. Nava-Zuazo, C.; Estrada-Soto, S.; Guerrero-Álvarez, J.; León-Rivera, I.; Molina-Salinas, G.M.; Said-Fernández, S.; Chan-Bacab, M.J.; Cedillo-Rivera, R.; Moo-Puc, R.; Mirón-López, G.; et al. Design, synthesis, and in vitro antiprotozoal, antimycobacterial activities of $\mathrm{N}-\{2-[$ (7-chloroquinolin-4yl)amino]ethyl\}ureas. Bioorg. Med. Chem. 2010, 18, 6398-6403. [CrossRef] [PubMed]

48. Boechat, N.; Pinheiro, L.C.S.; Santos-Filho, O.A.; Silva, I.C. Design and synthesis of new $\mathrm{N}$-(5-trifluoromethyl)-1H-1,2,4-triazol-3-yl benzenesulfonamides as possible antimalarial prototypes. Molecules 2011, 16, 8083-8097. [CrossRef]

49. Carvalho, R.C.C.; Martins, W.A.; Silva, T.P.; Kaiser, C.R.; Bastos, M.M.; Pinheiro, L.C.S.; Krettli, A.U.; Boechat, N. New pentasubstituted pyrrole hybrid atorvastatin-quinoline derivatives with antiplasmodial activity. Bioorg. Med. Chem. Lett. 2016, 26, 1881-1884. [CrossRef] 
50. Gudipati, S.; Katram, S.; Komati, S.; Kudavalli, S.J. Amorphous atorvastatin calcium. WO Patent 2,006,039,441 A2, 13 April 2006.

51. Silva, T.B.; Bernardino, A.M.R.; Ferreira, M.L.G.; Rogerio, K.R.; Carvalho, L.J.M.; Boechat, N.; Pinheiro, L.C.S. Design, synthesis and anti-P. falciparum activity of pyrazolopyridine-sulfonamide derivatives. Bioorg. Med. Chem. 2016, 24, 4492-4498. [CrossRef]

52. Manach, C.L.; Paquet, T.; Brunschwig, C.; Njoroge, M.; Han, Z.; Cabrera, D.G.; Bashyam, S.; Dhinakaran, R.; Taylor, D.; Reader, J.; et al. A novel pyrazolopyridine with in vivo activity in Plasmodium berghei- and Plasmodium falciparum-infected mouse models from structure-activity relationship studies around the core of recently identified antimalarial imidazopyridazines. J. Med. Chem. 2015, 58, 8713-8722. [CrossRef]

53. Bernardino, A.M.R.; Azevedo, A.R.; Pinheiro, L.C.S.; Borges, J.C.; Carvalho, V.L.; Miranda, M.D.; Meneses, M.D.F.; Nascimento, M.; Ferreira, D.; Rebello, M.A.; et al. Synthesis and antiviral activity of new 4-(phenylamino)/4-[(methylpyridin-2-yl)amino]-1-phenyl-1Hpyrazolo[3,4- $b$ ]pyridine-4-carboxylic acids derivatives. Med. Chem. Res. 2007, 16, 352-369. [CrossRef]

54. Bernardino, A.M.R.; Pinheiro, L.C.S.; Rodrigues, C.R.; Loureiro, N.I.; Castro, H.C.; Lanfredi-Rangel, A.; Sabatini-Lopes, J.; Borges, J.C.; Carvalho, J.M.; Romeiro, G.A.; et al. Design, synthesis, SAR, and biological evaluation of new 4-(phenylamino)thieno[2,3-b]pyridine derivatives. Bioorg. Med. Chem. 2006, 14, 5765-5770. [CrossRef]

55. Silveira, F.F.; Feitosa, L.M.; Mafra, J.C.M.; Ferreira, M.L.G.; Rogerio, K.R.; Carvalho, L.J.M.; Boechat, N.; Pinheiro, L.C.S. Synthesis and anti-Plasmodium falciparum evaluation of novel pyrazolopyrimidine derivatives. Med. Chem. Res. 2018, 27, 1876-1884. [CrossRef]

56. Santos, M.S.; Bernardino, A.M.R.; Pinheiro, L.C.S.; Canto-Cavalheiro, M.M.; Leon, L.L. An efficient synthesis of new 5-(1-aryl-1H-pyrazole-4-yl)-1H-tetrazoles from 1-aryl-1H-pyrazole-4-carbonitriles via [3 + 2]cycloaddition reaction. J. Heterocyclic Chem. 2012, 49, 1425-1428. [CrossRef]

57. Soliman, A.M.; Sultan, A.A.; El Remaily, M.A.A.; Abdel-Ghany, H. Synthesis of some novel fused azole derivatives. Synth. Commun. 2012, 42, 2748-2762. [CrossRef]

58. da Silva, R.M.R.J.; Gandi, M.O.; Mendonça, J.S.; Carvalho, A.S.; Coutinho, J.P.; Aguiar, A.C.C.; Krettli, A.U.; Boechat, N. New hybrid trifluoromethylquinolines as antiplasmodium agents. Bioorg. Med. Chem. 2019, 27, 1002-1008. [CrossRef] [PubMed]

59. Ohnmacht, C.J.; Patel, A.R.; Lutz, R.E. Antimalarials. 7. Bis(trifluoromethyl)- $\alpha-(2-$ piperidyl)-4quinolinemethanols. J. Med. Chem. 1971, 14, 926-928. [PubMed]

60. Meshram, H.M.; Reddy, B.C.; Kumar, D.A.; Kalyan, M.; Ramesh, P.; Kavitha, P.; Rao, J.V. Synthesis and cytotoxicity of new quinoline derivatives. Ind. J. Chem. 2012, 51B, 1411-1416.

61. Witkowski, B.; Khim, N.; Chim, P.; Kim, S.; Ke, S.; Kloeung, N.; Chy, S.; Duong, S.; Leang, R.; Ringwald, P.; et al. Reduced Artemisinin Susceptibility of Plasmodium falciparum Ring Stages in Western Cambodia. Antimicrob. Agents Chemother. 2013, 57, 914-923. [CrossRef] [PubMed] 